\title{
An Evolutionary Based Strategy for Predicting Rational Mutations in G Protein-Coupled Receptors
}

\author{
Miguel Angel Fuertes*, Carlos Alonso \\ Department of Microbiology, Centre for Molecular Biology "Severo Ochoa”, Spanish National Research Council and Autonomous \\ University, Madrid, Spain
}

Email address:

calonso@cbm.csic.es (C. Alonso), mafuertes@cbm.csic.es (M. A. Fuertes)

${ }^{*}$ Corresponding author

\section{To cite this article:}

Miguel Angel Fuertes, Carlos Alonso. An Evolutionary Based Strategy for Predicting Rational Mutations in G Protein-Coupled Receptors. Ecology and Evolutionary Biology. Vol. 6, No. 3, 2021, pp. 53-77. doi: 10.11648/j.eeb.20210603.11

Received: April 24, 2021; Accepted: May 11, 2021; Published: July 13, 2021

\begin{abstract}
Capturing conserved patterns in genes and proteins is important for inferring phenotype prediction and evolutionary analysis. The study is focused on the conserved patterns of the G protein-coupled receptors, an important superfamily of receptors. Olfactory receptors represent more than $2 \%$ of our genome and constitute the largest family of $\mathrm{G}$ protein-coupled receptors, a key class of drug targets. As no crystallographic structures are available, mechanistic studies rely on the use of molecular dynamic modelling combined with site-directed mutagenesis data. In this paper, we hypothesized that human-mouse orthologs coding for $\mathrm{G}$ protein-coupled receptors maintain, at speciation events, shared compositional structures independent, to some extent, of their percent identity as reveals a method based in the categorization of nucleotide triplets by their gross composition. The data support the consistency of the hypothesis, showing in ortholog G protein-coupled receptors the presence of emergent shared compositional structures preserved at speciation events. An extreme bias in synonymous codon usage is observed in both the conserved and non-conserved regions of many of these receptors that could be potentially relevant in codon optimization studies. The analysis of their compositional structures would help to design new evolutionary based strategies for rational mutations that would aid to understand the characteristics of individual $G$ protein-coupled receptors, their subfamilies and the role in many physiological and pathological processes, supplying new possible drug targets.
\end{abstract}

Keywords: Evolution, Triplet Composon, Ortholog, G-protein Coupled Receptor, Odorant Receptor

\section{Introduction}

G protein-coupled receptors (GPCRs) are integral membrane proteins used by cells to convert extracellular signals into intracellular responses. Inferred from their sequence and their structural similarities these receptors form a superfamily of membrane proteins containing many different families $[1,2]$ amongst which the aminergic GPCRs, are targets for $\sim 25 \%$ of current drugs [3]. The analysis of sequences in an evolutionary context suggests that dimerization appears to occur quite generally in GPCRs [4]. More than $50 \%$ of GPCRs are orphan receptors $[5,6]$ sharing common structural motifs in which seven transmembrane helices are connected to three extracellular loops and to three intracellular loops (see Figure 1A), being activated by a variety of external stimuli [7]. In general, they are targets for the bulk of therapeutic drugs, playing important roles in many biological processes $[8,9]$.

GPCRs tend to have conserved functional motifs in mammalian genomes making them distinguishable from other proteins. They present conserved compositional patterns in transmembrane helices and in extracellular and cytosolic loops [10]. Even though many members of the GPCR family have a large number of functional and structural similarities, they lack extensive sequence similarities. Thus, while over 40 GPCRs have been crystalized, the structure of not even one member of the largest GPCRs family, the olfactory receptors (ORs), has been determined. The poor functional heterologous expression, the post-translational modifications, the high flexibility, and the low stability in detergent hampering the understanding of the molecular mechanism of the OR 
function [11-13]. The ability to release and identify specific smells is a key feature for survival of most animals [14]. The mechanism of odor recognition is still lagging and will require solving multiple structures in complex with native ligands. In fact, the residues involved in the dynamic process that converts an inactive OR structure into an active one are still obscure. The latest advances in strategies leading to the structural resolution of GPCRs makes this goal to be realistic [15]. The high-resolution structures of specific GPCRs have provided insights that help the understanding of the relationship between the chemical structure of a ligand and the way it affects the conformation of the receptor [16]. However, there are not available crystallographic structures of ORs, therefore, most studies regarding the mechanistic analysis of ORs function have to be relied on the use of molecular dynamic modelling [17]. Certain clues regarding potential residues involved in the OR activation have been tentatively proposed, but they remain to be assessed by means of in vitro experiments and molecular dynamic simulations [18-19].

Recently, an analysis of human-mouse orthologs by the triplet composon method (or tCP-method) has shown new categorizations characterized by specific tCP-usages [20]. The bulk of human-mouse orthologs analyzed were categorized in 18 clusters [21]. One of those categorizations contains mostly genes coding for transmembrane proteins, in their majority GPCRs, and mainly ORs [21] although a widerange categorization of these receptor have not carry out yet. Lately, a variant of the tCP-method has been used to search for common DNA patterns distributed along the length of orthologs. In a large number of cases, appearing shared nucleotide structures between orthologs interspersed along the protein coding ORFs $[22,23]$. The aim of the study was to identify novel compositional structures interspersed in GPCRs that could be useful for site-directed mutagenesis and potentially relevant in seeking new drug targets.

\section{Methods}

\subsection{Gene Sample}

GPCRs were downloaded from the HUGO Gene Nomenclature Committee (HGNC) https://www.genenames. org/gene families/GPCRA\#ADRAA at the European Bioinformatics Institute (EBI) [24]; additional entries were downloaded from the Human Olfactory Data Explorer (HORDE) http://bioportal.weizmann.ac.il/HORDE// [25], the GeneCards database from the Weizmann Institute of Science [26], with Copyright C1996-2018, http://www.genecards. org/, and the Ensembl release 92, April 2018 OEMBL-EBI, http://www.ensembl.org. We only include in our study DNA from the longest transcripts.

The dataset used in the study contain 546 and 573 human and mouse GPCRs, respectively, among which 200 are human ORs and 400 mouse ORs (Table 2). The orthologs are identified by the name, the protein description and the number of shared tCPs. The table shows many human ORs having several mouse orthologs, and vice versa [27]. The parameters to state orthology in the Ensembl databank are in http://www.ensembl.org. Working with ortholog genes are needed among species for drawing genomic changes along their evolution. The comparison of mouse and human orthologs is of particular interest because mouse is often used as a model organism to understand human biology and however, both species are evolutionary distant [28]. The nomenclature used is the commonly used for human olfactory receptors [29], e.g. OR3A1 would correspond to the human olfactory receptor, family 3 , subfamily A, member 1 . In mouse we use, to avoid confusion, the official symbols given by the Mouse Genome Informatics (MGI) Nomenclature Group from the Jackson Laboratory, Bar Harbor, Maine, http://informatics. jax.org [30], e.g. Olfr10.

Table 1. $t C P$ code. List of composons ( $t C P s)$ and their associated nucleotide triplets.

\begin{tabular}{ll}
\hline $\mathbf{t C P}$ & DNA-triplets associated to tCPs \\
\hline$<\mathrm{A}>$ & AAA \\
$<\mathrm{T}>$ & TTT \\
$<\mathrm{G}>$ & GGG \\
$<\mathrm{C}>$ & CCC \\
$<\mathrm{AC}>$ & AAC, CAA, ACA, CCA, ACC, CAC \\
$<\mathrm{AT}>$ & AAT, TAA, ATA, TTA, ATT, TAT \\
$<\mathrm{AG}>$ & AAG, GAA, AGA, GGA, AGG, GAG \\
$<\mathrm{CG}>$ & CCG, GCC, CGC, GGC, CGG, GCG \\
$<\mathrm{GT}>$ & GGT, TGG, GTG, TTG, GTT, TGT \\
$<\mathrm{CT}>$ & CCT, TCC, CTC, TTC, CTT, TCT \\
$<$ AGC $>$ & AGC, GCA, CAG, ACG, CGA, GAC \\
$<$ AGT $>$ & AGT, GTA, TAG, ATG, TGA, GAT \\
$<$ ACT $>$ & ACT, CTA, TAC, ATC, TCA, CAT \\
$<$ TCG $>$ & TCG, CGT, GTC, TGC, GCT, CTG \\
\hline
\end{tabular}

\subsection{Brief Description to the tCP Method}

The tCP method counts NT triplets of a genomic sequence read fully overlapping categorizing them by their gross composition (Table 1). The justification for this method is theoretical and based on the existence of exclusionary multiplets characterized by the presence or absence of particular bases. The number of categorizations (called 'triplet-composons' or tCPs), resulted to be 14 and the optimal length for the multiplet was 3 NTs (a triplet) [20]. In summary, 14 tCPs contain all possible nearest-neighbors that can be formed with the four DNA bases. In order to take into account all and every one of the contexts of each NT, the sequence is read 'fully overlapping', guaranteeing that all triplets be considered to avoid losses of information. We assume, when reading the sequence in non-overlapping way, that the lost triplets could supply relevant evolutionary information. The notation of tCPs and their associated sets of NT-triplets are in Table 1.

\subsection{Numerical Analysis}

As an example, the distribution of tCPs in the human Betaadrenergic receptor $\left(\beta_{2} \mathrm{AR}\right)$ codified by the ADRB2 gene, was calculated (Figure 1a). The receptor mediates the catecholamine-induced activation of adenylate cyclase through the action of GPCRs [31-33]. We have used a variant 
of the original tCP-method [21] to analyze the cumulative tCP-usage frequency distribution (Figure 1B) along the gene sequence $[22,23]$. In the figure it can be observed the cumulative graph and the trend line for the usage frequency of the $\mathrm{tCP}<\mathrm{AG}>$. The cumulative tCP-usage would be, then, the sum of all previous tCP-appearances along the sequence up to the current length. In order to facilitate the study of the distribution of tCPs along of the ADRB2 sequence, the cumulative tCP-graph and the trend line (Figure 1b) were projected on the length axis (Figure 1c) by subtracting the cumulative tCP-usage frequency from the regression line, hereafter named 'tCP-profile' [22-23]. The tCP-profile represents the distribution of differences between the tCPevents observed, $t C P o$, and the estimated, $t C P e$. We will consider that two ortholog sequences share a similar tCPprofile when their Pearson correlation coefficient $(r)$ is equal or higher than $r \geq 0.85$. Coincidences in short stretches of the tCP-profile reduce notably the correlation coefficient of the complete sequence. We sought to impose a sufficiently stringent cut-off because it is known that an excess similarity implies common ancestry and consequently two homologous sequences showing a high correlation coefficient would guarantee a causal link with function [34]. On the other hand, in our GPCR sample, we want to avoid many ortholog sequences with low similarity but clearly homologous based on statistically significant structural similarity or strong sequence similarity to an intermediate sequence. Graphs and statistics were carried out with the package OriginPro 8 SRO V8.0724 (B724) COriginLab Corporation. Each one of the 14 tCPs listed in Table 1 has its own characteristic tCPdistribution that allows us to compare them between species. We represent in a panel the comparison of the 14 different tCP-profiles of each human-mouse ortholog from the dataset.

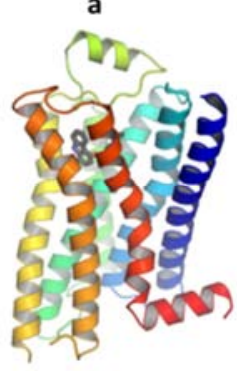

b

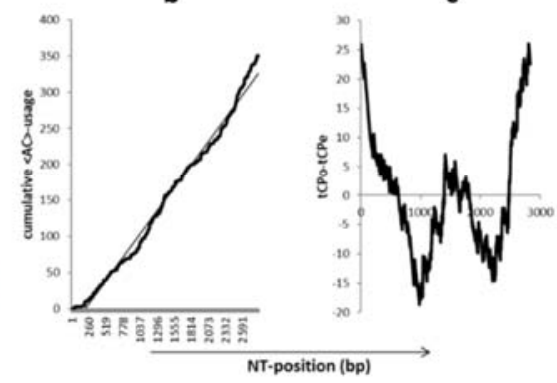

Figure 1. (a) The human beta-2 adrenergic receptor (ADRB2) in complex with the partial inverse agonist carazolol [31-33]. (b) Cumulative plot of events for the $t C P<A G>$ in ADRB2 (thick line) and their corresponding trend line (thin line). (c) Profile of $A D R B 2$ for $\langle A G\rangle$ representing the distribution of differences between the tCP-events observed, $t C P o$, and the estimated, tCPe.

\subsection{Differences Between the tCP Method and Current Methods}

The tCP method deeply differs from other current methods, not in the sequence comparison metrics but what is the object of measure. Usually, we measure identity between sequences when the object of the measurement is, for example, a NT sequence. In the tCP method the sequence comparison metrics does not change at all but does so the measure object; it is not a NT sequence but a tCP sequence. Thus, the first task to be done would be to transform a NT sequence to a tCP sequence. To do that, it is necessary read ortholog sequences in "fully overlapping way" stablishing for each nucleotide all their nearest neighbors and categorizing them by their gross composition by using Table 1 . We count, then, the frequency of appearance of each tCP along both sequences to obtain from the profiles, the conserved tCPs; this let us to locate the conserved stretches in both tCP sequences. Afterwards, we locate the conserved fragments in the NT sequences.

\subsection{Criteria Used to Highlight the Shared tCPs Along the Gene Length}

The tCPs shared by orthologs were obtained as follows: i) NT-sequences of human-mouse orthologs were translated into tCP-sequences using Table 1. ii) To compare sequences, we use the dynamic algorithm shaped for the global alignment of two sequences $[35,36]$. iii) A graphical representation of the data (the tCP-profile) was made, and iv) the level of similarity between the aligned tCP-sequences of each human-mouse ortholog was computed using the Pearson correlation coefficient (r). As control of non-random tCPdistributions along the genes, we analyzed the tCP-profiles of randomly generated sequences having NT-compositions identical to the orthologs. The utility shuffleseq from the EMBOSS explorer was used to generate the random sequences maintaining the NT composition [37, 38]. We confirmed also that identical NT-sequences have identical tCP-profiles as expected (data not shown).

\section{Results}

\section{1. tCP-Compositional Patterns in a Representative Ortholog GPCR}

To determine whether there are tCP-compositional patterns shared by human-mouse ortholog-GPCRs requires to generate the tCP-profile of each pair of ortholog sequences in order to be compared. To illustrate the process, we will use, as an example, the human-mouse ortholog, ADRB2 (Figure 1a). This ortholog shows high NT-percent similarity (85\%), moderate tCP-percent similarity $(67 \%)$ and similar tCP profiles in both species (see Table 2).

Figure 2 shows a panel representing the $14 \mathrm{tCP}$-profiles of ADRB2. The numerical inset shows the correlation coefficients of each tCP when comparing both orthologs; 3 out of 14 tCPs show correlation coefficients higher than the cut-off, namely, $<\mathrm{AG}>,<\mathrm{GT}>$ and $<\mathrm{AGC}>$ showing similar profiles to each other; consequently, many of NT-triplets associated with those tCPs would be shared by both orthologs. The remaining tCPs show correlation coefficients ranging from $r=0.36$ for $\langle\mathrm{T}>$ to $r=0.83$ for $\langle\mathrm{CT}>$. Although only tCP-profiles showing correlation coefficients higher than the cut-off were considered, we also observed short 
highly correlated fragments in some tCP-profiles, as it would be the case of $\langle\mathrm{CT}>$, $\langle\mathrm{TCG}>$ and $\langle\mathrm{GC}>$, with correlation coefficients near but lower the cut-off; they were discarded from the analysis although they contribute substantially to the percent of nucleotide identity between both orthologs. Lower correlation coefficients ranging from $0.36<\mathrm{r}<0.63$, were also observed for tCPs $<\mathrm{A}>,<\mathrm{T}>,<\mathrm{G}>,<\mathrm{C}>,<\mathrm{AC}>,<\mathrm{AT}>$ and $<$ ACT $>$.

We have obtained in a similar way to ADRB2, the shared tCP-profiles of all human-mouse pairs of ortholog sequences from the dataset (see Table 2).

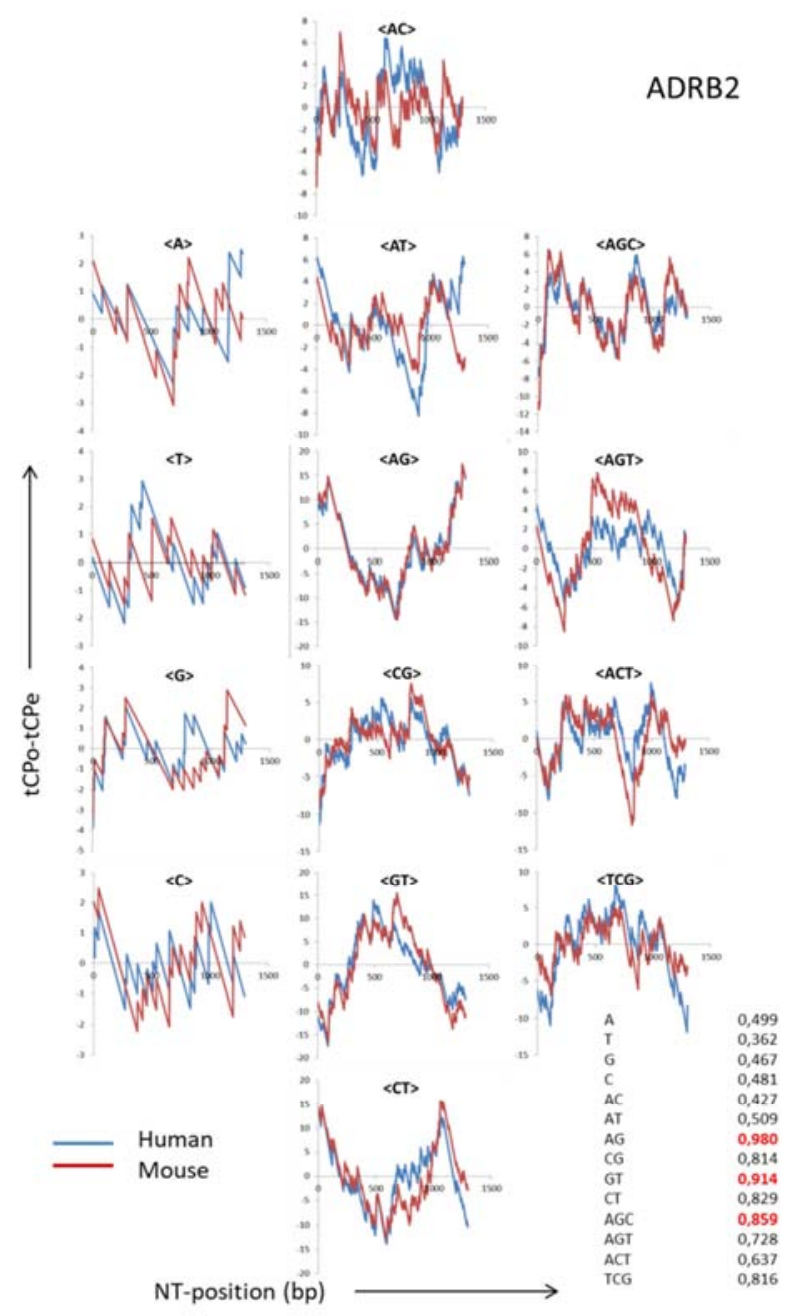

Figure 2. Comparison of tCP-profiles from the human-mouse ortholog ADRB2. Red and blue lines correspond to the profiles of mouse and human, respectively. The insets display the name of the ortholog (upper right corner), and a table with the Pearson correlation coefficient, $r$, between $t C P$ profiles of human and mouse (lower right corner). Pearson correlation coefficient for $r \geq 0.85$ are in red.

\subsection{The Conserved tCP Structure Between Orthologs is Under Selection Constraints in GPCRs}

We investigated the emergent compositional structures shared by human-mouse ortholog GPCRs to study whether there are evidences of constraints for variability. NTmismatches in three human-mouse orthologs of the LGR family were investigated, and also three genes of the OR family, namely, LGR4, LGR5, LGR6, OR52E6 (Olfr671), OR8J (Olfr1045) and OR7A10 (Olfr1351), all of them different in their tCP usage and in the type and number of conserved tCPs. It was observed that LGR4 conserves 2 tCPs, namely, $<\mathrm{G}>$ and $<\mathrm{TCG}>$, LGR5 conserves 8 tCPs, $<\mathrm{A}>,\langle\mathrm{T}>,<\mathrm{AC}>,<\mathrm{AT}>,<\mathrm{AG}>,\langle\mathrm{CG}>,<\mathrm{GT}>$, and $\langle\mathrm{CT}>$, LGR6 conserves $8 \mathrm{tCPs},<\mathrm{A}>,<\mathrm{AC}>,<\mathrm{AT}>,<\mathrm{AG}>,<\mathrm{CG}>$, $<\mathrm{GT}>,<\mathrm{ACT}>$ and $<\mathrm{TCG}>$, OR52E6 $($ Olfr671) conserves 2 tCPs, $<\mathrm{T}>$ and $<\mathrm{CT}>$, OR8J1 (Olfr1045) conserves 4 tCPs, $<\mathrm{G}>, \quad<\mathrm{AT}>,<\mathrm{AG}>$ and $<\mathrm{AGT}>$ and finally, OR7A10 (Olfr1351) conserves $2 \mathrm{tCPs},<\mathrm{G}>$ and $<\mathrm{AC}>$. To see the tCPs conserved in more ortholog GPCRs see Table 2. The analysis compares the percent of NT mismatches in regions in which the orthologs analyzed share the conserved tCPs, relative to the percent of NT mismatches observed in those regions in which only one of the genes contains the conserved tCPs. The results are in the bar diagram of Figure 3 and show that in GPCRs, the ortholog shared regions present low percentages of NT mismatches, in contrast with those regions in which only one ortholog have the conserved tCPs being the difference highly significant in average $(p<0.0001)$. Although evolutionary changes occur at speciation events, data suggest, however, that shared regions would be under evolutionary constrains for variability reinforcing the idea that such compositional structures would be conserved at speciation events.
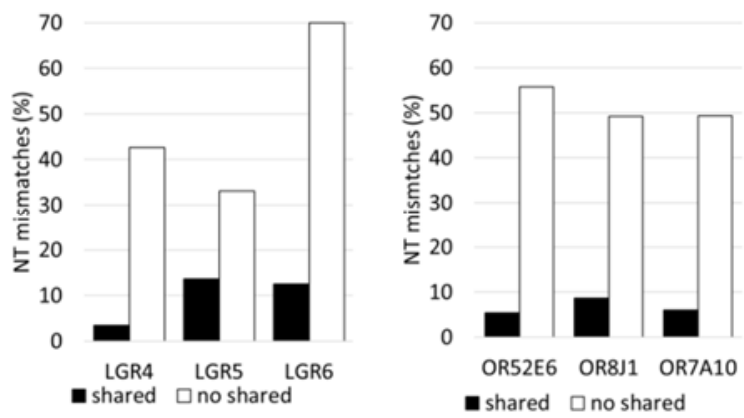

Figure 3. Bar diagram showing the percent NT mismatches in regions in which the orthologs compared share the conserved tCPs (black bars) relative to the percent NT mismatches in regions in which only one of the orthologs contains conserved tCPs (white bars).

\subsection{Statistical Data of Shared tCPs from Human-Mouse Ortholog-GPCRs}

Figure 4 shows the statistical data obtained from the Table 2. When representing the percent of GPCRs sharing a given tCP (Figure $4 \mathrm{a}$ ) we observed that $<\mathrm{AG}>$ is the tCP shared for more than $58 \%$ of human-mouse orthologs, indicating that, at speciation events, although evolutionary changes occur more frequently, there are in GPCRs long gene regions evolutionary constricted to maintain the use of triplets containing all nearest neighbors of $\mathrm{A}$ and $\mathrm{G}$. Apart from the tCP $<\mathrm{AG}>$, tCPs more frequently shared are $<\mathrm{CT}>(35 \%)$ and $<\mathrm{GT}>(27 \%)$ respectively. On the other hand, $<\mathrm{AGC}>$ $(12 \%)$ and $<\mathrm{AT}>(13 \%)$ respectively, are the less shared tCPs.

Figure $4 \mathrm{~b}$ shows the percent of GPCRs sharing a given 
number of tCPs. The study of ORs and GPCR-non-ORs shows significant differences in the percent of shared tCPs. Thus, $75 \%$ ORs share less than 4 tCPs while most of all ORs do not share more than 5 tCPs. However, 70\% GPCR-nonORs share less than 6 tCPs while practically all of them do not share more than 9 tCPs. None of the OR shares more than 8 tCPs in contrast with GPCR-non-ORs that share up to 12 tCPs as is the case of FZD4, a gene codifying for the frizzled-4 receptor (see Table 2). It may be due to the restrictive cut-off imposed. Only a few ORs (12\%) and GPCR-non-ORs $(6 \%)$ do not share any tCP for the cut-off considered.

\section{a}

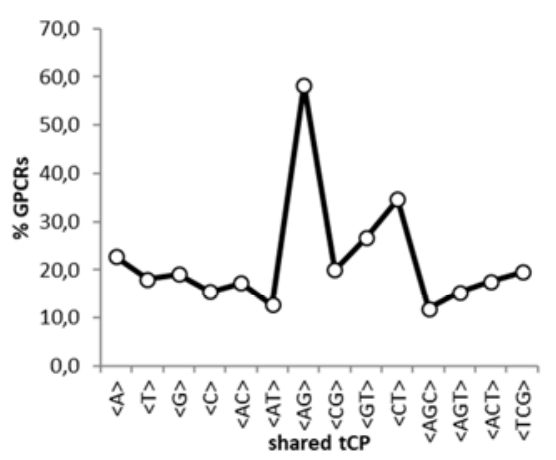

b

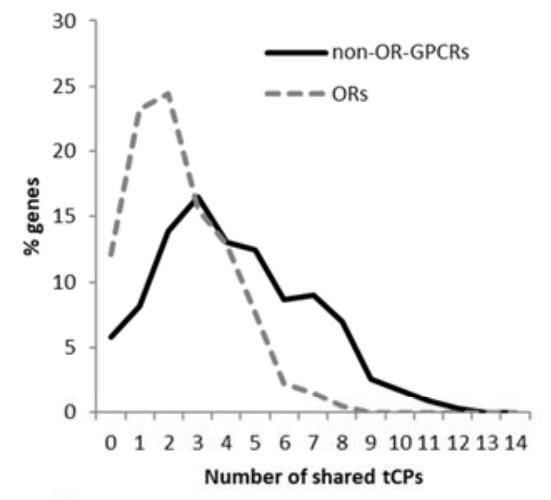

C

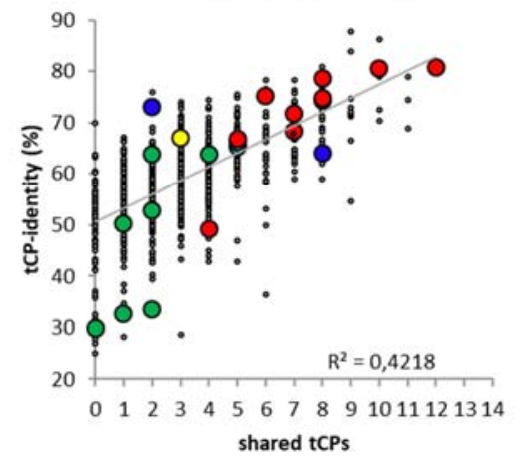

Figure 4. Information collected from the ortholog dataset. (a) Plot representing the percent orthologs sharing a given tCP. (b) Graph representing the percent orthologs sharing a given number of tCPs. The dashed line (---) represents ORs and the continuous line (-) represents GPCR-non-ORs. (c) Point plot representing, for each ortholog, the number of $t C P$ s shared between species against their percent of tCP similarity. The grey line represents the regression line and the corresponding determination coefficient $R^{2}$. Colored big dots represent specific orthologs considered in more detail: LGR4 and LGR5 (dark blue), mouse orthologs of the human OR3A1 (green), frizzled orthologs (red), human ADRB2 (yellow).

Figure $4 \mathrm{c}$ shows a point graph representing the percent similarity of each sequence alignment against the number of shared tCPs. As it can be observed, for a given number of shared tCPs there are a notable number of ortholog-GPCRs with different percent similarity. For example, for a percent similarity of $60 \%$ we can find ortholog-GPCRs sharing a number of tCPs ranging from 0 to 9 . The notable dispersion observed suggests that there is a significant degree of independence between the percent similarity and the amount of shared tCPs. In any case, the regression line shows a positive slope indicating that in some cases higher identities correlate with higher number of shared tCPs as it would be expected. However, this is not the general rule. The dispersion in the percent similarity is higher as the number of shared tCPs decreases because a higher number of orthologGPCRs share a lower number of tCPs as it was mentioned in Figure $4 b$.

An analysis of Figure $4 \mathrm{c}$ and Table 2 let us to obtain evolutionary data from functionally similar ortholog GPCRs having high percent NT-identity and however very different number of shared tCPs. The amount of ortholog sequences meeting those requirements is not very extensive (Table 2). We selected two human GPCRs, LGR4, LGR5 and their mouse orthologs, to carry out a more detailed study. We have not special reasons for the election of LGR4 and LGR5 beyond illustrate an analysis of a pair of related orthologs with very dissimilar compositional characteristics (Figure 4c) and because they contain a large leucine-rich extracellular domain for hormone or neurotransmitters binding [39, 40], attributes making them suitable for a more detailed analysis about the synonymous codon usages of leucine in the different domains of the protein.

\subsection{Ortholog-GPCRs Highly NT Identical: The Case of the Leucine Rich Repeat Containing GPCRs LGR4 and LGR5}

We will study in LGR4 and LGR5 and their mouse orthologs: i) the dissimilarities among them as well as the number of shared tCPs; ii) the evolutionary constrains observed in the shared regions and iii) the synonymous codon usages in the tCP conserved regions. LGR4 and its mouse ortholog are identical in length (2856 base pairs) and also LGR5 and its ortholog (2724 base pairs); they are highly similar in NT-sequence ( $89 \%$ between LGR4 and its ortholog and $84 \%$ between LGR5 and its ortholog). Figure 5a shows a large extracellular domain in LGR4 and LGR5 with multiple leucine-rich repeats mediating ligand interaction, in addition to seven transmembrane domains codified in exon 18 of both genes, and an intracellular domain for signal transduction [41]. The main dissimilarities between LGR4 and LGR5 (Figures $5 \mathrm{~b}$ and $5 \mathrm{c}$ ) have to do with the number of shared tCPs; two tCPs shared by the human-mouse ortholog LGR4 $(<\mathrm{G}>$ and $<\mathrm{TCG}>$ ) and eight tCPs by the human-mouse ortholog LGR5 $(<\mathrm{A}>,<\mathrm{T}>,<\mathrm{AC}>,<\mathrm{AT}>,<\mathrm{AG}>,<\mathrm{CG}>$, $<\mathrm{GT}>$ and $<\mathrm{CT}>$ ). As can be observed, LGR4 and LGR5 do not share any tCP for $r \geq 0.85$ despite the fact that both are adrenergic receptors, both are part of the same evolutionary family and they are similar in 3D structure. Figures 8 and 9 
illustrate the complete panels showing the shared tCPs of LGR4 and LGR5 and their mouse orthologs. The high correlation observed in the shared tCPs is consequence of the full length comparison of both LGR4 and LGR5 and their mouse counterparts.

\subsection{Synonymous Codon Preferences for Leucine in the Human-Mouse Orthologs, LGR4 and LGR5}

LGR proteins harbor a distinctive large extracellular domain with 17 leucine-rich repeats composed of 24 amino acids [42]. We search for possible similarities and dissimilarities in the number and the type of synonymous codons encoding leucine in this external region relative to the transmembrane domain and/or the inner domain of binding to G-protein (Figure 5a).
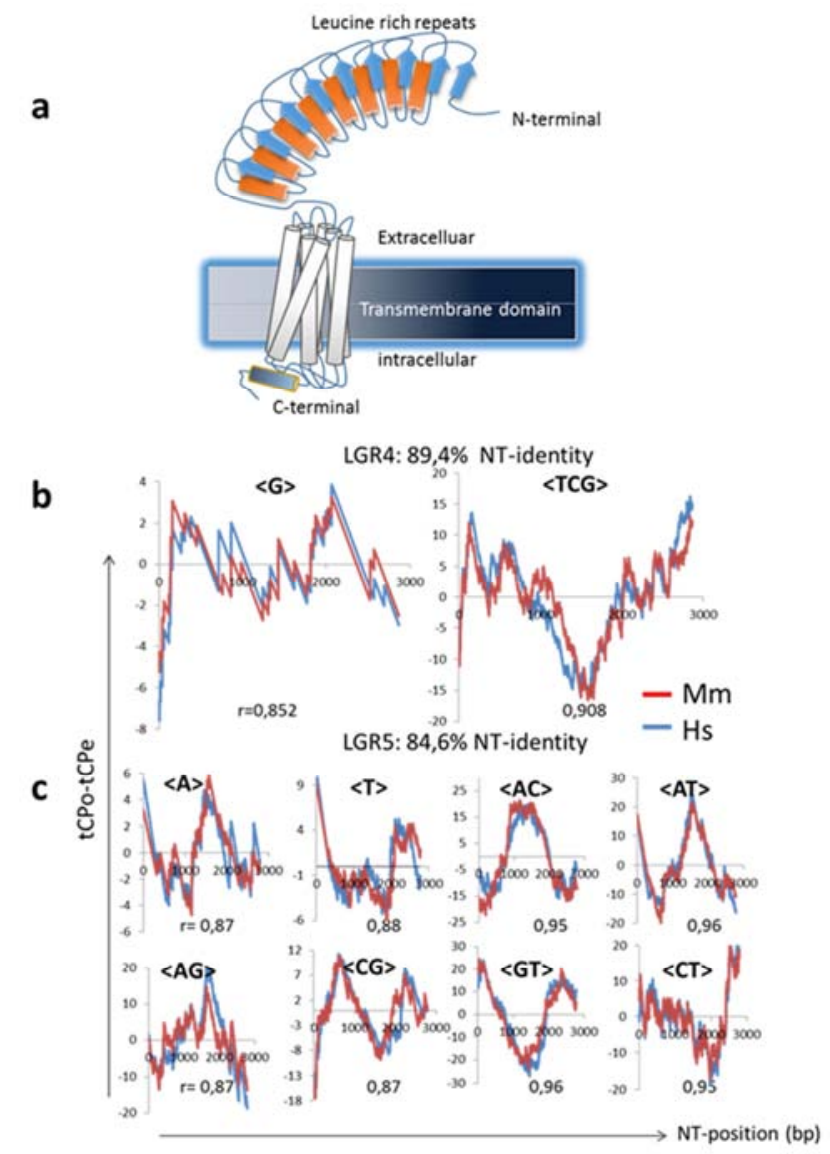

Figure 5. (a) Scheme showing the structure of the LGR family. Shared tCPS in LGR4 (b) and LGR5 (c); red and blue lines represent tCP-profiles of the mouse and the human, respectively. Identification of shared tCPs and their Pearson correlation coefficients between tCP-profiles (upper and lower side of each profile, respectively). Percent NT-similarity (in upper part of graphs (b) and (c))

Figure 6 shows the differences observed in the synonymous codon-usage for leucine, in human LGR4 and LGR5, inside and outside the regions containing the conserved tCPs in both orthologs (Figures $4 \mathrm{~b}$ and 4c). LGR4 conserves the tCPs $<\mathrm{G}>$ and $<\mathrm{TCG}>$. It can be observed that $<\mathrm{G}>$ and $<\mathrm{TCG}>$ contain a unique codon codifying for leucine, the CTG codon, (Table 1). Consequently, the CTG codon would be always $100 \%$ preferred inside the regions containing the 2 conserved $\mathrm{tCPs}<\mathrm{G}>$ and $<\mathrm{TCG}>$ being absent outside these regions. The remaining synonymous codons encoding leucine TTA (23\%), TTG (25\%), CTT (20\%), CTC (13\%), and CTA (19\%) appear exclusively outside the regions containing the conserved tCPs of LGR4, representing a total of $100 \%$, as expected. On the other hand, LGR5 conserved the tCPs $<\mathrm{A}>,<\mathrm{T}>,<\mathrm{AC}>,<\mathrm{AT}>,<\mathrm{AG}>$, $<\mathrm{CG}>,<\mathrm{GT}>$, and $<\mathrm{CT}>$. It can be observed that those tCPs contain four codons codifying for leucine, CTC, TTG, CTT and TTA, (Table 1). Consequently, those codons would be always preferred inside the regions containing the conserved tCPs with percentages CTC (30\%), TTG (25\%), CTT (26\%) and TTA (19\%) representing a total of $100 \%$ being absent outside these regions. The remaining synonymous codons encoding leucine in LGR5, CTG (83\%) and CTA (17\%) appear exclusively outside the conserved regions, representing also a total of $100 \%$.

Results as those obtained for LGR4 and LGR5, are obtained for other human-mouse orthologs with multiple leucine-rich repeats sharing some tCP-profiles. The extreme synonymous codon preference for leucine occurs, then, not only in the external region of the multiple leucine-rich repeats but in all domains of these receptors being a consequence of the tCPs categorization rule (Table 1). The result can be generalized to any ortholog GPCR sharing some tCP-profiles.

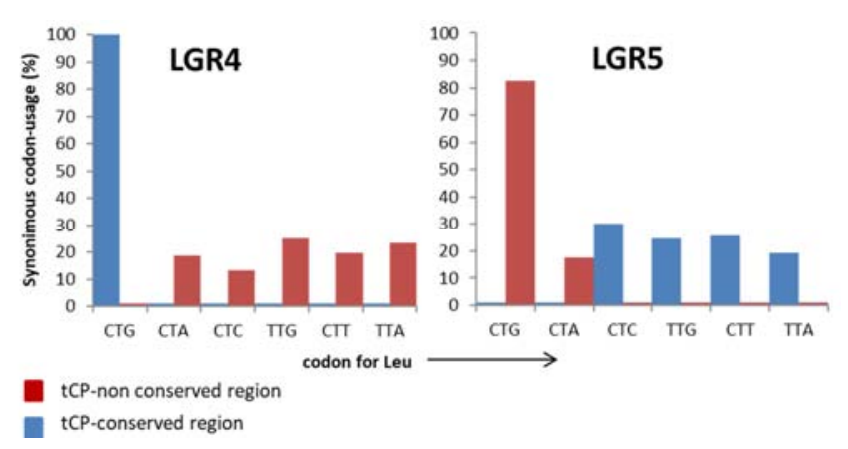

Figure 6. Differences in the synonymous codon-usage for leucine in the tCP conserved (blue bars) and non-conserved (red bars) regions of LGR4 and LGR5.

\subsection{The issue of Identifying Human-Mouse OR Orthologs by Automated Methods}

Many orthologs used in the study would be inaccurate because databases work, in many cases, with automated methods for ortholog identification. The decision (about to be or not to be an ortholog) depends on the parameters used by those automated software's, given sometimes inaccurate results to each other. Ensembl and GeneCards databases were used in this paper and we observed that, in fact, such dissimilarities exist. We think, maybe the research carried out in this paper could shed light in this area. Table 2 shows that a given human OR could have one or more ortholog in mouse and vice versa [27]. However, in different databanks there are dissimilarities about the amount of orthologs between both species. As the decision depends on the 
parameters used by those automated methods, we will try to

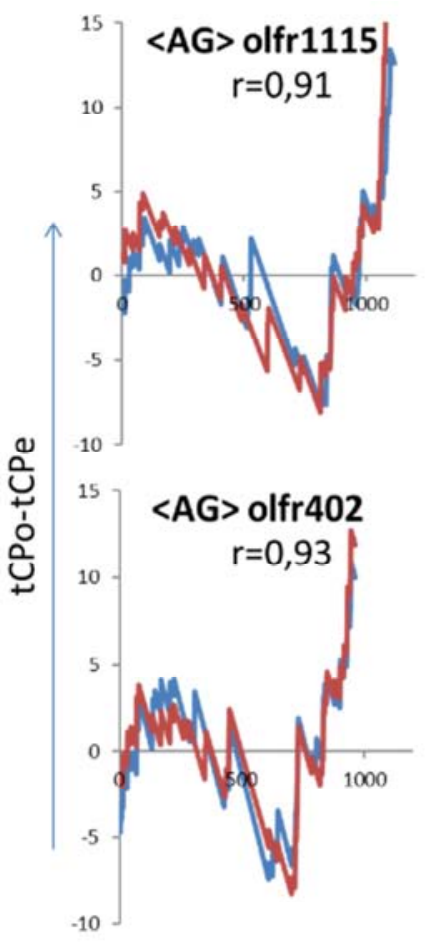

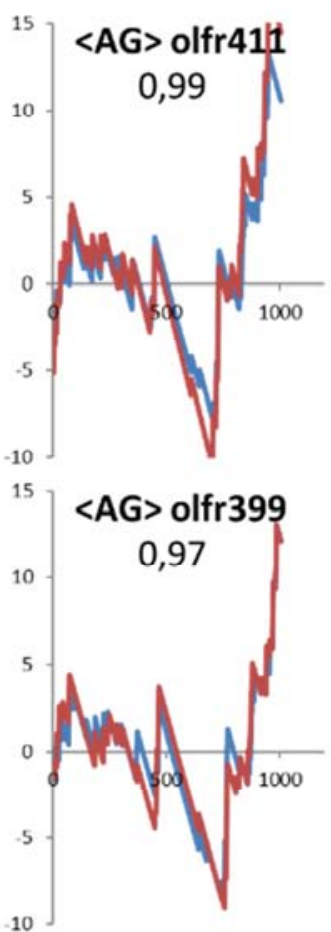

NT-position (bp) study the behavior of the tCP method in this cases.

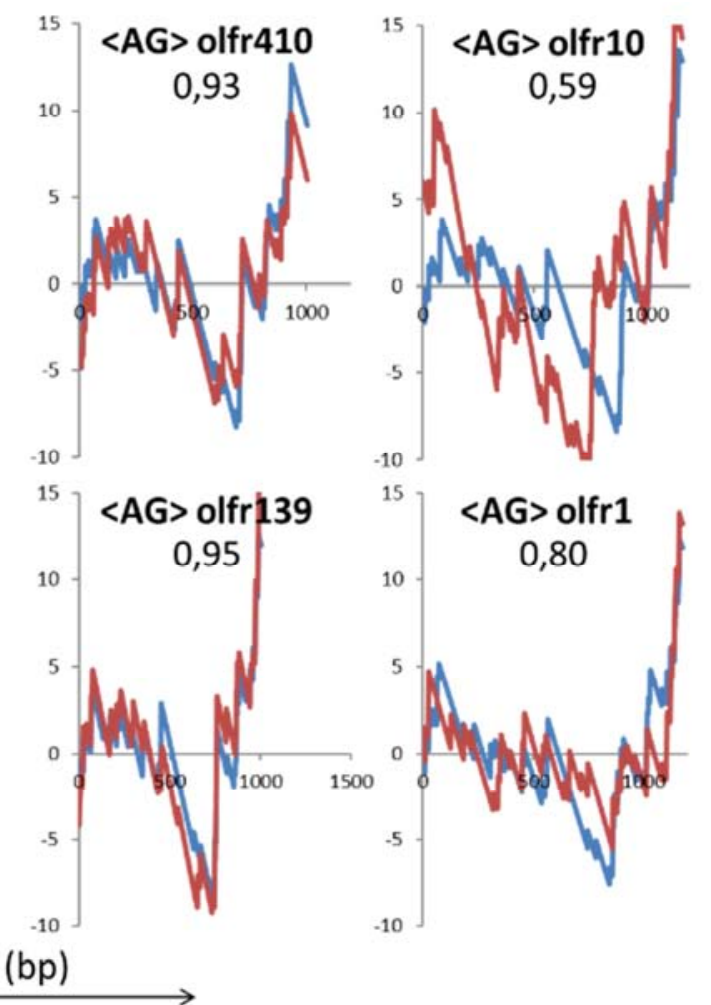

Figure 7. Red and blue lines correspond to tCP-profiles of the human OR3A1 and their mouse orthologs Olfr1115, Olfr411, Olfr410, Olfr402, Olfr399, Olfr 139 and Olfr 1 , respectively. The upper side of each $t C P$-profile shows the identification of the shared $t C P,\langle A G\rangle$, the name of the mouse ortholog and the Pearson correlation coefficients (r) between OR3A1 and its mouse orthologs.

As an example, GeneCards indicates that mouse Olfr1115, Olfr411, Olfr410. Olfr10. Olfr402, Olfr399, Olfr139 and Olfrl would be orthologs of the human OR3A1, a gene included in the human GPCR-1 family. On the other hand, Ensembl databank indicates that only Olfr 402 and Olfr 410 would be orthologs of OR3A1. A tCP-profile analysis of those genes shows, however, that the $\mathrm{tCP}<\mathrm{AG}>$ would be common to Olfr1115, Olfr411, Olfr410, Olfr 402, Olfr 399 and Olfr 139 with $\mathrm{r} \geq 0.85$ but $<\mathrm{AG}>$ would be common neither to Olfr10 nor Olfr1; both genes show correlations lower than the cut-off when they are compared with OR3A1 (Figure 7). In fact, Olfr 10 does not have any shared tCP with OR3A1, and Olfr 1 shows two shared tCPs, $<\mathrm{AT}>$ and $<\mathrm{CG}>$, but none in common with OR3A1 (Table 2). High correlation coefficients were obtained when $<\mathrm{AG}>$-profiles of OR3A1 and those of Olfr1115, Olfr411, Olfr410. Olfr402, Olfr399 and Olfr 139 were compared; in all cases $\mathrm{r} \geq 0.91$ except Olfr 1 $(\mathrm{r}=0.80)$ and Olfr10 $(\mathrm{r}=0.59)$, respectively. Looking at the Olfrl profile we observe certain resemblance with OR3A1 $(\mathrm{r}=0.80)$ despite the fact that, at speciation events, the human gene changed significantly relative its mouse ortholog exhibiting significant variations in composition. In the case of Olfr10, we think that changes accumulated are so significant $(\mathrm{r}=0.59)$ that we have doubts about whether OR3A1 and Olfr10 can be considered orthologs. Based on the high correlation observed, we would conclude that Olfr1115, Olfr411, Olfr410. Olfr402, Olfr399 and Olfr139 could be orthologs of the human OR3A1 because two orthologous sequences showing a high correlation coefficient would imply a common ancestry [34]; Olfr 10 and Olfrl, however, would be dubious, although in this case could not be discounted that they be orthologs since it assumes that two sequences with low similarity can be orthologous based on statistically significant structural similarity or strong sequence similarity to an intermediate sequence [34].

\section{Discussion}

The amount and importance of GPCRs have interested of experts of many fields [15, 43, 44]. Efforts have been made to elucidate the structure of GPCRs [45]. However, the low number of crystalized GPCRs and the absence of crystallographic data in ORs requires that most mechanistic studies rely on the use of molecular dynamic modelling combined with site-directed mutagenesis data [43] despite the number of restrictions that this type of studies convey. Limited attention has been devoted in the development of new evolutionary based strategies for predicting rational mutations in GPCRs. This is a critical aspect for the interpretation of pharmacological and physiological experiments if conclusions are taken between species [46]. To this end, we will discuss an evolutionary strategy that could be useful to predict rational mutations in GPCRs in general, and in ORs in particular.

The strategy consists in considering all sets of NT triplets with identical gross composition (Table 1); then, reading the 
sequence fully overlapping, we count the cumulative frequency of appearance of each one of the sets along the sequence making a comparative graphic (the tCP-profile) between the analyzed sequence and its ortholog (see Materials and Methods). Figure 2 illustrates the tCP-profile of the GPCR ADRB2 and its mouse counterpart, codifying for the $\beta 2 A R$ adrenergic receptor [47]. Only three tCPs show correlation coefficients higher than the cut-off and only one, the tCP $<\mathrm{AG}>$, shows a correlation coefficient close to unity $(\mathrm{r}=0.98)$; this high correlation indicates in both species, a highly similar $<\mathrm{AG}>$ distribution along both orthologs. The correlation coefficients for the remaining $11 \mathrm{tCP}$-profiles are, however, significantly lower. From data, we conclude that high percent NT similarity between orthologs do not imply higher number of shared tCPs (Figure 4c). similar study was performed for the remaining GPCRs from the dataset (see Table 2). Figure 4c also shows that the amount of shared tCPs in a notable fraction of orthologs varies linearly around the regression line with the percent tCP similarity; higher is the similarity, higher is the amount of shared tCPs and vice versa. For percent similarities higher than $70 \%$, the convergence of data supports that two sequences $100 \%$ NTidentical would share $100 \%$ of tCPs, validating, consequently, the consistency of the process. Among others, many frizzled genes, playing a critical role in the regulation of cell polarity [48], meet the criteria set out above. These genes (Table 2), share a high number of tCPs (up to 12) and, therefore, high percent NT-identity with their mouse orthologs and therefore, a high degree of conservation interspecies. As the frizzled proteins are receptors for secreted Wnt proteins, the data support that the Wnt pathway would be evolutionarily ancient, as reported [49].

It can be observed that most GPCRs share less than 5 tCPs (Figure 4b), showing this region a large proportion of orthologs with high deviations around the mean and revealing remarkable composition patterns (Figure 4c); in this region, the number of shared tCPs and the percent NT identity do not correlate at all. In one case, the tCP compositional structures shown by orthologs in this region would not change notably at speciation events, being hard to find them because they would be often masked by the high percent of NT similarity observed as occur in ADRB2 (yellow point, Figure 4c). In the other case, the low NT percent similarity let us identify easily the underlying tCPcompositional structure shared by orthologs.

A case illustrating the precedent discussion would be of the human-mouse orthologs LGR4 and LGR5 both included in the group B of R-spondins [50]; they potentiate the $\mathrm{Wnt} / \beta$ catenin signaling pathway and stem cell growth factors, being both, closely related to cancer [42, 51]. LGR4 and LGR5, despite their high structural and functional similarity [42, 52], have orthologs sharing very different number of tCPs (blue points, Figure 4c). The conserved compositional structure of LGR4, is subtler ( 2 conserved tCPs with its counterpart in mouse) than in LGR5 (8 conserved tCPs). None tCP conserved in LGR5 is shared by LGR4 (Figure 5a) despite the possibility to have a common ancestor in the early metazoan evolution [50] and suggesting, that LGR5 would be evolutionary ancient than LGR4 because many of changes occurring in LGR5, at speciation events, would be less than those occurring in LGR4. A functional feature common in LGR4 and LGR5 that differentiates from other GPCRs is the large N-terminal domain composed by 17 leucine-rich repeats, containing 24 amino acids each [42]. Centering the attention on this extracellular domain, we wonder on what and how many of these synonymous codons are in this large external region as well as in other protein domains. Extreme differences were observed between the synonymous codons encoding leucine in the tCP conserved and non-conserved regions of LGR4 and LGR5. Differences occur in all domains of the protein, being these ones clearly dissimilar between LGR4 and LGR5. It is the first time that this extreme synonymous codon preference for leucine is described in LGRs and could be explained by the degeneration of the tCP code (Table 1).

It is well known that changes in synonymous codons could have unexpected effects many of them linked with disease $[53,54]$. Evidences reveal that synonymous codon selection in natural RNAs have evolved in response to selective pressures at both the RNA and protein levels [55]. In fact, high mRNA expression levels encode slow-evolving proteins in most organisms [56, 57]. It is known, that coding sequences accumulate non-synonymous substitutions at a slower rate than the synonymous substitution rate for correct protein folding and function [58]. In fact, Figure 3 indicates that compositional changes in GPCRs increase notably in tCP non-conserved regions relative to conserved regions, suggesting that optimal codons are significantly associated with conserved amino acids. This would be implying, as reported, that selection has placed optimal codons to diminish the consequences of translation errors in every organism and that optimal codon sets scored significantly higher than alternative sets in all organisms [59].

Lately, methods to improve protein production by using synonymous codon changes (codon-optimization) has been be reconsidered because it can affect the protein conformation and function [54, 59]. This paper provides an evolutionary approach to codon optimization by using the tCP-profile of ortholog sequences. The profile reveals the existence of evolutionary conserved tCPs in GPCR fragments, not previously detected. Results suggest that both, the set of optimal codons, and codon positions, interact to enhance translational precision warranting that codon bias can be significant for protein structure and function [58]. Data show, for each ortholog, that tCP conserved and nonconserved fragments show extreme synonymous codon preferences dissimilar to each other (Figure 6). Thus, the presence of the conserved compositional structure and the over usage of certain synonymous codons in those regions encourage us to suggest how we can modify the expression of some genes by synonymous codon optimization in order to avoid possible adverse effects on the protein conformation. Efforts are being done on the whole-genome synonymous codon substitution, a mechanism to create exclusive 
organisms exhibiting genetic isolation and enhanced biological functions [60]. The repurposing of codons would be a strategy for enhancing genomes with functions not commonly found in nature $[61,62]$. We think that the knowledge of these new conserved compositional structures would simplify notably the rational codon optimization design, circumventing or substituting synonymous codons in tCP conserved and non-conserved regions that would be important from the point of view of the structure and function.

Relative to ORs superfamily, it is categorized in at least nine divergent gene families, having little sequence similarity each and showing dramatic differences in size between species [63]. Moreover, during the vertebrate evolution the OR repertoire has expanded about 10-fold. Such diversification is likely to result from translocation, gene conversion, recombination, and/or duplication [64, 65]. Data herein reported suggest, however, that such divergence would be, to some extent, apparent and restricted to the reduced NT similarity between OR gene families. This suggests that although the NT similarity remains lower than that in nonOR-GPCRs, ORs retain the tCP compositional structures at speciation events when they sharing one or more tCPs. However, Figure $4 \mathrm{~b}$ indicates that for $\mathrm{r} \geq 0.85$, a significant fraction of GPCRs does not share any tCP between orthologs and that this proportion is notably higher for ORs than for non-OR-GPCRs, supporting data showing the low percent similarity observed between different OR families. The absence of resolved high-resolution structures in ORs have hampered an in-depth understanding into their molecular mechanism [11-13]. However, the tCP compositional structure suggests a new point of view to address the issue by supplying new conserved motifs previously unavailable and indicating that changes in these tCP motifs probably would affect the function of GPCRs. This occurs with many GPCRs of the rhodopsin family having several conserved transmembrane domains [66] whose study suggests that changes in those residues often result in misfolding of GPCRs [67]. In fact, some sites in the DNA are more prone to mutations than others and one would expect to find an excess of them that are polymorphic in not shared regions of orthologs. Receptor mutations in conserved transmembrane residues, however, selectively disrupt one pathway of a receptor coupled to multiple pathways [68-69]. For similar reasons we think that the tCP compositional structures preserved over millions of years [22 23] could be key evolutionary elements for fitness with potential to be used in mutation studies.

Now, we will discuss something about the amount and the type of orthologs detected when different algorithms are used in distinct databanks; For example, Figure 7 shows all mouse orthologs we have found of the human OR3A1 in both GeneCards and Ensembl. To test the response of the tCP method to this issue, we compared the tCP-profiles of all of them. The comparison was exclusively based in the tCP composition properties of the entire sequence length, not in local similarities. Results suggest that differences between databanks are consequence of the parameters used to discriminate orthologs, giving results, as in this case, very divergent between each other. The tCP method test results (Figure 7) are nearer to those obtained by Ensembl suggesting in this case that GeneCards would underestimate the number of mouse orthologs of OR3A1. In any case, analyzing carefully tCP-profiles of all mouse orthologs of OR3A1 proposed by the Ensembl algorithm, the tCP method suggests a dubious case (Olfr 1$)$ and a negative case (Olfr 10$)$. This occurs frequently and an analysis case-by-case would be required. Despite a significant fraction of ORs have lacking shared tCPs (Figure 4B), relevant evolutionary information could be obtained by tuning down the cut-off of tCP-profiles considering correlations lower but near the cut-off in the analysis. A scrutiny of such information could be useful to clarify data as those of the Olfr1 and Olfr10 (Figure 7) considered orthologs of OR3A1 by the Ensembl algorithm.

Highest NT percent similarities between orthologs not always reveal useful evolutionary information, masking, however, the shared tCP structures hidden behind the high NT similarity. The knowledge of tCPs conserved deduced from the analysis of tCP-profiles are useful to reveal such compositional structures. Thus, the mutation dynamics outside of the shared compositional structures (Figure 3) would explain why some GPCRs of the same functional family might evolve to different levels of complexity by adaptation to the environment because it is known that the divergence between orthologous would promote the evolution of novel functions. The data indicate that the shared tCP compositional structures between orthologs observed in evolutionary distant species would change very little being more reticent to mutate than those non shared ones [22, 23]. Table 2 supply information of many GPCRs to readers and for which we have only seen few examples, in order to illustrate the hypothesis proposed.

\section{Conclusions}

As a summary, we would highlight the following facts: i) identical NT sequences generate identical tCP sequences, but identical tCP sequences generate a plethora of different NT sequences due to the degeneration of the tCP code (Table 1); this open the possibility of having NT mismatches in DNA fragments tCP conserved letting to tCP conserved regions a certain degree of flexibility at NT level necessary to adaptation to the environment. However, NT mismatches in tCP conserved region are few in number compared with those observed in non-conserved tCP regions (Figure 3). ii) There are NT-misaligned fragments that can supplying useful evolutionary information, and the tCP-profile allows identifying them. iii) The degeneration of the tCP code (Table 1) would explain the extreme synonymous codon usage in the conserved compositional structures and in the nonconserved regions between ortholog-GPCRs (Figure 5). iv) The paper expands the concept of homology taking into account the percent similarity between tCP sequences containing, as a particular case, the NT percent similarity. 


\section{Appendix}

Table 2. List of human-mouse ortholog GPCRs analyzed. In parentheses, after the human OR, we indicated the name of the counterpart OR in mouse following the nomenclature of the international databases. Some human ORs have annotated more than one mouse ortholog and vice versa. The cut-off for conserved $t C P s$ is $r \geq 0.85$.

\begin{tabular}{|c|c|c|c|c|c|}
\hline $\mathbf{N}^{\mathbf{0}}$ & Gene name & Description & Shared tCPs & tCP identity (\%) & Gaps (\%) \\
\hline 1 & ADORA1 & Adenosine receptor A1 & 4 & 72,8 & 4,9 \\
\hline 2 & ADORA2A & Adenosine receptor $2 \mathrm{~A}$ & 7 & 62 & 7,4 \\
\hline 3 & ADORA2B & Adenosine receptor $2 \mathrm{~B}$ & 3 & 71,4 & 4,2 \\
\hline 4 & ADORA3 & Adenosine receptor 3 & 0 & 58,8 & 8,7 \\
\hline 5 & ADRA1A & Alpha-1A adrenergic receptor & 7 & 70,4 & 2,9 \\
\hline 6 & ADRA1B & Alpha-1B adrenergic receptor & 3 & 50,5 & 39,9 \\
\hline 7 & ADRA1D & Alpha-1D adrenergic receptor & 5 & 61,6 & 11,7 \\
\hline 8 & ADRA2A & Alpha-2A adrenergic receptor & 8 & 71,2 & 6,4 \\
\hline 9 & ADRA2B & Alpha-2B adrenergic receptor & 5 & 63,6 & 8,7 \\
\hline 10 & ADRA2C & Alpha-2C adrenergic receptor & 8 & 69,1 & 9,8 \\
\hline 11 & ADRB1 & Beta-1 adrenergic receptor & 5 & 75,2 & 8,1 \\
\hline 12 & ADRB2 & Beta-2 adrenergic receptor & 3 & 67,1 & 7,7 \\
\hline 13 & ADRB3 & Beta-3 adrenergic receptor & 5 & 59,1 & 12,7 \\
\hline 14 & AGTR1 & Type-1 angiotensin II receptor & 5 & 67,9 & 0,6 \\
\hline 15 & AGTR2 & Type-2 angiotensin II receptor & 6 & 76,6 & 2,7 \\
\hline 16 & AGTRL1 & Apelin receptor A & 4 & 71 & 3 \\
\hline 17 & AVPR1A & Vasopressin V1a receptor & 5 & 62,2 & 8,9 \\
\hline 18 & AVPR1B & Vasopressin V1b receptor & 4 & 63,5 & 8 \\
\hline 19 & AVPR2 & Vasopressin V2 receptor & 1 & 62,4 & 7 \\
\hline 20 & BAI1 & Adhesion $\mathrm{G}$ protein-coupled receptor B1 & 6 & 71,3 & 5,3 \\
\hline 21 & BAI2 & Adhesion $\mathrm{G}$ protein-coupled receptor B2 & 8 & 76,7 & 3,9 \\
\hline 22 & BAI3 & Adhesion $\mathrm{G}$ protein-coupled receptor B3 & 8 & 80,9 & 1 \\
\hline 23 & BDKRB1 & B1 bradykinin receptor & 1 & 54,9 & 17,4 \\
\hline 24 & BDKRB2 & $\mathrm{B} 2$ bradykinin receptor & 1 & 60,6 & 11,8 \\
\hline 25 & BRS3 & Bombesin receptor subtype- 3 & 7 & 71,1 & 3,5 \\
\hline 26 & C3AR1 & $\mathrm{C} 3 \mathrm{a}$ anaphylatoxin chemotactic receptor & 4 & 53,3 & 11,3 \\
\hline 27 & C5AR1 & C5a anaphylatoxin chemotactic receptor 1 & 1 & 46,5 & 18,3 \\
\hline 28 & CALCR & Calcitonin receptor & 2 & 51,9 & 18,6 \\
\hline 29 & CALCRL & Calcitonin gene-related peptide type 1 receptor & 3 & 63,7 & 6,4 \\
\hline 30 & CASR & Extracellular calcium-sensing receptor & 10 & 70,3 & 3,4 \\
\hline 31 & CCBP2 & Atypical chemokine receptor 2 & 2 & 55,4 & 11,1 \\
\hline 32 & CCKAR & Cholecystokinin receptor type A & 5 & 67,9 & 4,7 \\
\hline 33 & CCKBR & Gastrin/cholecystokinin receptor type B & 5 & 65,7 & 7,4 \\
\hline 34 & CCR10 & C-C chemokine receptor type 10 & 7 & 64,6 & 8,1 \\
\hline 35 & CCR2 & $\mathrm{C}-\mathrm{C}$ chemokine receptor type 2 & 3 & 52,3 & 16,5 \\
\hline 36 & CCR3 & C-C chemokine receptor type 3 & 3 & 52,9 & 10,5 \\
\hline 37 & CCR4 & C-C chemokine receptor type 4 & 3 & 61,6 & 6,4 \\
\hline 38 & CCR5 & $\mathrm{C}-\mathrm{C}$ chemokine receptor type 5 & 2 & 64,4 & 5,6 \\
\hline 39 & CCR6 & C-C chemokine receptor type 6 & 1 & 50,7 & 12,7 \\
\hline 40 & CCR7 & C-C chemokine receptor type 7 & 3 & 58,2 & 21,2 \\
\hline 41 & CCR8 & C-C chemokine receptor type 8 & 3 & 53,5 & 14,9 \\
\hline 42 & CCR9 & C-C chemokine receptor type 9 & 4 & 64,6 & 6,1 \\
\hline 43 & CCRL1 & $\mathrm{C}-\mathrm{C}$ chemokine receptor-like 1 & 2 & 62,3 & 1,9 \\
\hline 44 & CCRL2 & $\mathrm{C}-\mathrm{C}$ chemokine receptor-like 2 & 2 & 43,3 & 20,2 \\
\hline 45 & CCXCR1 & Chemokine $\mathrm{XC}$ receptor 1 & 1 & 52,5 & 13,9 \\
\hline 46 & CD97 & CD97 antigen & 3 & 45,8 & 22,5 \\
\hline 47 & CELSR1 & Cadherin EGF LAG seven-pass G-type receptor 1 & 7 & 59,1 & 9,8 \\
\hline 48 & CELSR2 & Cadherin EGF LAG seven-pass G-type receptor 2 & 4 & 70,1 & 2,9 \\
\hline 49 & CELSR3 & Cadherin EGF LAG seven-pass G-type receptor 3 & 7 & 69 & 3,9 \\
\hline 50 & CHRM1 & Muscarinic acetylcholine receptor M1 & 7 & 78,3 & 1,5 \\
\hline 51 & CHRM2 & Muscarinic acetylcholine receptor M2 & 8 & 74,7 & 1,7 \\
\hline 52 & CHRM3 & Muscarinic acetylcholine receptor M3 & 7 & 69,3 & 4,8 \\
\hline 53 & CHRM4 & Muscarinic acetylcholine receptor M4 & 7 & 72,8 & 2,4 \\
\hline 54 & CHRM5 & Muscarinic acetylcholine receptor M5 & 8 & 73,7 & 1,1 \\
\hline 55 & CMKLR1 & Chemokine-like receptor 1 & 4 & 60,9 & 11,3 \\
\hline 56 & CMKOR1 & Atypical chemokine receptor 3 & 3 & 74 & 3,4 \\
\hline 57 & CNR2 & GTP-binding nuclear protein GSP2/CNR2 & 2 & 57,1 & 9,5 \\
\hline 58 & CRHR1 & Corticotropin-releasing factor receptor 1 & 8 & 77,9 & 1 \\
\hline 59 & CRHR2 & Corticotropin-releasing factor receptor 2 & 2 & 39,5 & 45,9 \\
\hline 60 & $\mathrm{CXCR} 2$ & $\mathrm{C}-\mathrm{X}-\mathrm{C}$ chemokine receptor type 2 & 0 & 56,2 & 9,5 \\
\hline
\end{tabular}




\begin{tabular}{|c|c|c|c|c|c|}
\hline $\mathbf{N}^{\circ}$ & Gene name & Description & Shared tCPs & tCP identity (\%) & Gaps (\%) \\
\hline 61 & CXCR3 & C-X-C chemokine receptor type 3 & 5 & 61,1 & 8,3 \\
\hline 62 & CXCR4 & C-X-C chemokine receptor type 4 & 3 & 69,8 & 2,7 \\
\hline 63 & CXCR5 & C-X-C chemokine receptor type 5 & 2 & 60,1 & 7,8 \\
\hline 64 & CXCR6 & C-X-C chemokine receptor type 6 & 0 & 57,9 & 6 \\
\hline 65 & CYSLT1 & Cysteinyl leukotriene receptor 1 & 8 & 68,9 & 6,5 \\
\hline 66 & CYSLT2 & Cysteinyl leukotriene receptor 2 & 2 & 48,4 & 21,6 \\
\hline 67 & DARC & Atypical chemokine receptor 1 & 4 & 45,1 & 16,7 \\
\hline 68 & DRD1 & D (1) dopamine receptor & 3 & 69,2 & 2 \\
\hline 69 & DRD2 & D (2) dopamine receptor & 6 & 71,2 & 7,7 \\
\hline 70 & DRD3 & D (3) dopamine receptor & 5 & 64 & 13,7 \\
\hline 71 & DRD4 & D (4) dopamine receptor & 4 & 60,8 & 18 \\
\hline 72 & DRD5 & D (5) dopamine receptor & 4 & 61,3 & 10,5 \\
\hline 73 & EBI2 & G-protein coupled receptor 183 & 2 & 58,4 & 8,3 \\
\hline 74 & EDG1 & Sphingosine 1-phosphate receptor 1 & 5 & 71,7 & 2,1 \\
\hline 75 & EDG2 & Lysophosphatidic acid receptor 1 & 7 & 73,2 & 5,6 \\
\hline 76 & EDG3 & Sphingosine 1-phosphate receptor 3 & 3 & 67,8 & 4,1 \\
\hline 77 & EDG4 & Lysophosphatidic acid receptor 2 & 5 & 68,6 & 7,4 \\
\hline 78 & EDG5 & Sphingosine 1-phosphate receptor 2 & 4 & 60 & 10,9 \\
\hline 79 & EDG6 & Sphingosine 1-phosphate receptor 4 & 2 & 56,9 & 7,7 \\
\hline 80 & EDG7 & Lysophosphatidic acid receptor 3 & 3 & 64,1 & 6 \\
\hline 81 & EDG8 & Sphingosine 1-phosphate receptor 5 & 1 & 56,3 & 14,8 \\
\hline 82 & EDNRA & Endothelin-1 receptor & 3 & 64,7 & 2 \\
\hline 83 & EDNRB & Endothelin receptor type B & 6 & 68,5 & 4,2 \\
\hline 84 & ELTD1 & Adhesion G protein-coupled receptor L4 & 4 & 54,9 & 14 \\
\hline 85 & EMR1 & Adhesion G protein-coupled receptor E1 & 2 & 52,6 & 13,6 \\
\hline 86 & EMR4 & Adhesion $\mathrm{G}$ protein-coupled receptor E4 & 0 & 37,1 & 39,9 \\
\hline 87 & F2RL1 & Proteinase-activated receptor 2 & 3 & 59,2 & 9,6 \\
\hline 88 & F2RL2 & Proteinase-activated receptor 3 & 2 & 52 & 7,8 \\
\hline 89 & F2RL3 & Proteinase-activated receptor 4 & 2 & 52,5 & 15,7 \\
\hline 90 & FFA1R & Free fatty acid receptor 1 & 3 & 54,5 & 10 \\
\hline 91 & FFA2R & Free fatty acid receptor 2 & 4 & 51,8 & 18,8 \\
\hline 92 & FFA3R & Free fatty acid receptor 3 & 6 & 61,5 & 8,7 \\
\hline 93 & FPR1 & fMet-Leu-Phe receptor & 0 & 52,3 & 11,5 \\
\hline 94 & FPRL1 & $\mathrm{N}$-formyl peptide receptor 3 & 0 & 49,1 & 19,9 \\
\hline 95 & FSHR & Follicle-stimulating hormone receptor & 11 & 68,8 & 2,8 \\
\hline 96 & FZD1 & Frizzled-1 & 8 & 74,3 & 4,6 \\
\hline 97 & FZD2 & Frizzled-2 & 8 & 78,7 & 5,7 \\
\hline 98 & FZD3 & Frizzled-3 & 10 & 80,5 & 0,6 \\
\hline 99 & FZD4 & Frizzled-4 & 12 & 80,8 & 1,5 \\
\hline 100 & FZD5 & Frizzled-5 & 8 & 74,9 & 2,3 \\
\hline 101 & FZD6 & Frizzled- 6 & 4 & 49,3 & 29,2 \\
\hline 102 & FZD7 & Frizzled-7 & 6 & 75,2 & 4,4 \\
\hline 103 & FZD8 & Frizzled-8 & 7 & 71,8 & 7 \\
\hline 104 & FZD9 & Frizzled-9 & 5 & 65,4 & 9,6 \\
\hline 105 & FZD10 & Frizzled-10 & 7 & 68,3 & 3,2 \\
\hline 106 & GABABL & Probable G-protein coupled receptor 156 & 8 & 58,9 & 9,6 \\
\hline 107 & GABBR1 & Gamma-aminobutyric acid type B receptor subunit 1 & 2 & 66 & 14,8 \\
\hline 108 & GABBR2 & Gamma-aminobutyric acid type B receptor subunit 2 & 7 & 73,8 & 1,8 \\
\hline 109 & GALR1 & Galanin receptor type 1 & 7 & 70,8 & 3,3 \\
\hline 110 & GALR2 & Galanin receptor type 2 & 4 & 63,5 & 12 \\
\hline 111 & GALR3 & Galanin receptor type 3 & 8 & 70,5 & 9,6 \\
\hline 112 & GCGR & Glucagon receptor & 3 & 60,9 & 6,8 \\
\hline 113 & GHRHR & Growth hormone-releasing hormone receptor & 0 & 63,4 & 5,1 \\
\hline 114 & GHSR & Growth hormone secretagogue receptor type 1 & 8 & 75.8 & 2.7 \\
\hline 115 & GIPR & Gastric inhibitory polypeptide receptor & 4 & 60,2 & 12,5 \\
\hline 116 & GLP1R & Glucagon-like peptide 1 receptor & 3 & 67 & 8 \\
\hline 117 & GLP2R & Glucagon-like peptide 2 receptor & 1 & 61,3 & 11 \\
\hline 118 & GPBAR1 & G-protein coupled bile acid receptor 1 & 3 & 62,9 & 3,3 \\
\hline 119 & GPR120 & Free fatty acid receptor 4 & 7 & 63,9 & 10 \\
\hline 120 & GPR126 & Adhesion G-protein coupled receptor G6 & 2 & 61,9 & 8,6 \\
\hline 121 & GPR18 & G-protein coupled receptor 18 & 8 & 62,1 & 4,6 \\
\hline 122 & GPR19 & G-protein coupled receptor 19 & 5 & 58,7 & 10,7 \\
\hline 123 & GPR20 & G-protein coupled receptor 20 & 4 & 61,4 & 8,7 \\
\hline 124 & GPR21 & G-protein coupled receptor 21 & 7 & 76,3 & 0 \\
\hline 125 & GPR22 & G-protein coupled receptor 22 & 8 & 72,5 & 6,8 \\
\hline 126 & GPR23 & G-protein coupled receptor 23 & 2 & 76 & 0,8 \\
\hline 127 & GPR25 & G-protein coupled receptor 25 & 2 & 60,3 & 17,4 \\
\hline
\end{tabular}




\begin{tabular}{|c|c|c|c|c|c|}
\hline $\mathrm{N}^{\mathbf{0}}$ & Gene name & Description & Shared tCPs & tCP identity (\%) & Gaps (\%) \\
\hline 128 & GPR26 & G-protein coupled receptor 26 & 11 & 78,9 & 2,3 \\
\hline 129 & GPR27 & G-protein coupled receptor 27 & 9 & 83,9 & 2,9 \\
\hline 130 & GPR30 & G-protein coupled receptor 30 & 3 & 65,6 & 10,2 \\
\hline 131 & GPR31 & G-protein coupled receptor 31 & 2 & 48,9 & 13,2 \\
\hline 132 & GPR32 & G-protein coupled receptor 32 & 0 & 43,1 & 19,9 \\
\hline 133 & GPR33 & G-protein coupled receptor 33 & 4 & 56,5 & 11 \\
\hline 134 & GPR34 & G-protein coupled receptor 34 & 3 & 68,3 & 5,9 \\
\hline 135 & GPR35 & G-protein coupled receptor 35 & 1 & 55 & 18,3 \\
\hline 136 & GPR37 & G-protein coupled receptor 37 & 7 & 60,4 & 10,2 \\
\hline 137 & GPR37L1 & Prosaposin receptor GPR37L1 & 2 & 52,9 & 29,4 \\
\hline 138 & GPR39 & G-protein coupled receptor 39 & 4 & 50 & 10,7 \\
\hline 139 & GPR4 & G-protein coupled receptor 4 & 4 & 69,5 & 6,1 \\
\hline 140 & GPR44 & G-protein coupled receptor 44 & 2 & 60,3 & 10,7 \\
\hline 141 & GPR45 & G-protein coupled receptor 45 & 6 & 66,2 & 5,8 \\
\hline 142 & GPR50 & G-protein coupled receptor 50 & 5 & 59,2 & 12,6 \\
\hline 143 & GPR52 & G-protein coupled receptor 52 & 4 & 66,2 & 15 \\
\hline 144 & GPR55 & G-protein coupled receptor 55 & 1 & 60,1 & 7,5 \\
\hline 145 & GPR56 & G-protein coupled receptor 56 & 6 & 60,2 & 10,1 \\
\hline 146 & GPR6 & G-protein coupled receptor 6 & 5 & 68,4 & 6,1 \\
\hline 147 & GPR61 & G-protein coupled receptor 61 & 8 & 77,8 & 3,1 \\
\hline 148 & GPR62 & G-protein coupled receptor 62 & 3 & 62,6 & 12,6 \\
\hline 149 & GPR63 & G-protein coupled receptor 63 & 5 & 69,1 & 3,8 \\
\hline 150 & GPR64 & G-protein coupled receptor 64 & 5 & 63,2 & 11,8 \\
\hline 151 & GPR65 & G-protein coupled receptor 65 & 2 & 54,7 & 12,7 \\
\hline 152 & GPR68 & G-protein coupled receptor 68 & 4 & 68,1 & 7,1 \\
\hline 153 & GPR75 & G-protein coupled receptor 75 & 5 & 68,1 & 3,8 \\
\hline 154 & GPR77 & G-protein coupled receptor 77 & 1 & 43,6 & 25,8 \\
\hline 155 & GPR79 & G-protein coupled receptor 79 & 2 & 48,5 & 21,1 \\
\hline 156 & GPR81 & Hydroxycarboxylic acid receptor 1 & 3 & 59,3 & 10 \\
\hline 157 & GPR82 & Probable G-protein coupled receptor 82 & 4 & 68,3 & 3,1 \\
\hline 158 & GPR83 & Probable G-protein coupled receptor 83 & 1 & 64,8 & 11 \\
\hline 159 & GPR84 & G-protein coupled receptor 84 & 3 & 64,3 & 3,9 \\
\hline 160 & GPR85 & Probable G-protein coupled receptor 85 & 9 & 87,8 & 0,3 \\
\hline 161 & GPR87 & G-protein coupled receptor 87 & 3 & 64,4 & 4 \\
\hline 162 & GPR88 & Probable G-protein coupled receptor 88 & 8 & 77,3 & 3,7 \\
\hline 163 & GPR92 & Lysophosphatidic acid receptor 5 & 6 & 58,4 & 15,2 \\
\hline 164 & GPR97 & Adhesion $\mathrm{G}$ protein-coupled receptor $\mathrm{G} 3$ & 3 & 53,4 & 12,9 \\
\hline 165 & GPR101 & Probable G-protein coupled receptor 101 & 5 & 47 & 25,8 \\
\hline 166 & GPR103 & Pyroglutamylated RFamide peptide receptor & 4 & 52,8 & 24,8 \\
\hline 168 & GPR107 & Protein GPR107 & 5 & 63 & 7,8 \\
\hline 169 & GPR108 & G-protein coupled receptor 108 & 3 & 58,8 & 13,1 \\
\hline 170 & GPR109A & Hydroxycarboxylic acid receptor 2 & 1 & 64,6 & 7,7 \\
\hline 171 & GPR110 & Adhesion G-protein coupled receptor F1 & 1 & 50,7 & 15,7 \\
\hline 172 & GPR111 & Adhesion G-protein coupled receptor F2 & 1 & 43,8 & 31,2 \\
\hline 173 & GPR112 & Adhesion G-protein coupled receptor G4 & 4 & 47,3 & 19 \\
\hline 174 & GPR113 & Adhesion G-protein coupled receptor F3 & 2 & 42,6 & 26,8 \\
\hline 175 & GPR114 & Adhesion G-protein coupled receptor G5 & 2 & 46,7 & 21 \\
\hline 176 & GPR115 & Adhesion G protein-coupled receptor F4 & 4 & 49,7 & 15,8 \\
\hline 177 & GPR116 & Adhesion $\mathrm{G}$ protein-coupled receptor F5 & 2 & 50,3 & 18,6 \\
\hline 178 & GPR119 & Glucose-dependent insulinotropic receptor & 3 & 66,6 & 2,9 \\
\hline 179 & GPR120 & Free fatty acid receptor 4 & 6 & 63,9 & 10 \\
\hline 180 & GPR123 & Adhesion $\mathrm{G}$ protein-coupled receptor $\mathrm{A} 1$ & 0 & 25,1 & 62,7 \\
\hline 181 & GPR124 & Adhesion $\mathrm{G}$ protein-coupled receptor $\mathrm{A} 2$ & 5 & 64,2 & 8,9 \\
\hline 182 & GPR125 & Adhesion $\mathrm{G}$ protein-coupled receptor $\mathrm{A} 3$ & 0 & 60,4 & 12,5 \\
\hline 183 & GPR126 & Adhesion G-protein coupled receptor G6 & 2 & 61,9 & 8,6 \\
\hline 184 & GPR128 & Adhesion G-protein coupled receptor G7 & 2 & 53,2 & 13,1 \\
\hline 185 & GPR132 & Probable G-protein coupled receptor 132 & 2 & 50,7 & 20,7 \\
\hline 186 & GPR133 & Adhesion G-protein coupled receptor D1 & 0 & 50,5 & 22,5 \\
\hline 187 & GPR135 & Probable G-protein coupled receptor 135 & 5 & 59,6 & 15,2 \\
\hline 188 & GPR137B & Integral membrane protein GPR137B & 10 & 72,6 & 7 \\
\hline 189 & GPR137 & Integral membrane protein GPR137 & 4 & 58,7 & 24,4 \\
\hline 190 & GPR137C & Integral membrane protein GPR $137 \mathrm{C}$ & 5 & 42,9 & 44,7 \\
\hline 191 & GPR139 & Probable G-protein coupled receptor 139 & 5 & 74,8 & 3,5 \\
\hline 192 & GPR141 & Probable G-protein coupled receptor 141 & 0 & 60,4 & 5,4 \\
\hline 193 & GPR142 & Probable G-protein coupled receptor 142 & 2 & 46 & 29,2 \\
\hline 194 & GPR143 & G-protein coupled receptor 143 & 1 & 44,7 & 31,9 \\
\hline 195 & GPR144 & Adhesion G-protein coupled receptor D2 & 1 & 32 & 46,9 \\
\hline
\end{tabular}




\begin{tabular}{|c|c|c|c|c|c|}
\hline $\mathbf{N}^{\mathbf{0}}$ & Gene name & Description & Shared tCPs & tCP identity (\%) & Gaps (\%) \\
\hline 196 & GPR146 & Probable G-protein coupled receptor 146 & 3 & 54,2 & 14,7 \\
\hline 197 & GPR149 & Probable G-protein coupled receptor 149 & 6 & 36,5 & 45,9 \\
\hline 198 & GPR150 & Probable G-protein coupled receptor 150 & 3 & 53,2 & 18,2 \\
\hline 199 & GPR151 & Probable G-protein coupled receptor 151 & 5 & 62,4 & 6 \\
\hline 200 & GPR152 & Probable G-protein coupled receptor 152 & 6 & 53,1 & 19,6 \\
\hline 201 & GPR153 & Probable G-protein coupled receptor 153 & 7 & 63,6 & 8,8 \\
\hline 202 & GPR154 & Neuropeptide S receptor & 3 & 60,4 & 16 \\
\hline 203 & GPR157 & G-protein coupled receptor 157 & 4 & 63,3 & 7,7 \\
\hline 204 & GPR158L1 & Probable G-protein coupled receptor 179 & 9 & 54,7 & 12,6 \\
\hline 205 & GPR160 & Probable G-protein coupled receptor 160 & 0 & 41,4 & 19,5 \\
\hline 206 & GPR161 & G-protein coupled receptor 161 & 1 & 34,6 & 53,1 \\
\hline 207 & GPR162 & Probable G-protein coupled receptor 162 & 7 & 74,1 & 2,1 \\
\hline 208 & GPR165 & G protein-coupled receptor 165 & 0 & 51,4 & 18,8 \\
\hline 209 & GPR166P & $\mathrm{G}$ protein-coupled receptor $166 \mathrm{p}$ & 0 & 45,8 & 21 \\
\hline 210 & GPR171 & Probable G-protein coupled receptor 171 & 4 & 65,9 & 3,4 \\
\hline 211 & GPR172B & Solute carrier family 52 , riboflavin transporter, member 1 & 2 & 62,8 & 9,4 \\
\hline 212 & GPR173 & Probable G-protein coupled receptor 173 & 10 & 86,2 & 1,8 \\
\hline 213 & GPR174 & Probable G-protein coupled receptor 174 & 2 & 69,2 & 3,6 \\
\hline 214 & GPR175 & Transmembrane protein adipocyte-associted 1 & 0 & 58,5 & 20,4 \\
\hline 215 & GPR176 & G-protein coupled receptor 176 & 8 & 71,3 & 5 \\
\hline 216 & GPR177 & Protein wntless homolog & 6 & 74,6 & 1,1 \\
\hline 217 & GPR178 & Transmembrane protein 181 & 2 & 44,7 & 32,7 \\
\hline 218 & GPRC5A & Retinoic acid-induced protein 3 & 3 & 57,6 & 8,4 \\
\hline 219 & GPRC5B & G-protein coupled receptor family C group 5 member B & 6 & 67,9 & 6,6 \\
\hline 220 & GPRC5C & G-protein coupled receptor family $\mathrm{C}$ group 5 member $\mathrm{C}$ & 8 & 66 & 5,9 \\
\hline 221 & GPRC5D & G-protein coupled receptor family $\mathrm{C}$ group 5 member $\mathrm{D}$ & 2 & 58,9 & 5,9 \\
\hline 222 & GPRC6A & G-protein coupled receptor family C group 6 member A & 1 & 62,9 & 4,3 \\
\hline 223 & GRM1 & Metabotropic glutamate receptor 1 & 9 & 71,2 & 3,5 \\
\hline 224 & GRM2 & Metabotropic glutamate receptor 2 & 3 & 73,3 & 2 \\
\hline 225 & GRM3 & Metabotropic glutamate receptor 3 & 9 & 74,6 & 1,1 \\
\hline 226 & GRM4 & Metabotropic glutamate receptor 4 & 4 & 74,4 & 3,2 \\
\hline 227 & GRM5 & Metabotropic glutamate receptor 5 & 4 & 59,7 & 23,7 \\
\hline 228 & GRM6 & Metabotropic glutamate receptor 6 & 0 & 69,9 & 4,6 \\
\hline 229 & GRM7 & Metabotropic glutamate receptor 7 & 10 & 79 & 1,4 \\
\hline 230 & GRM8 & Metabotropic glutamate receptor 8 & 6 & 78,3 & 1,8 \\
\hline 231 & GRPR & Gastrin-releasing peptide receptor & 5 & 71,1 & 4,8 \\
\hline 232 & HCRTR1 & Orexin receptor type 1 & 6 & 71,2 & 7 \\
\hline 233 & HCRTR2 & Orexin receptor type 2 & 6 & 67,8 & 7 \\
\hline 234 & HRH1 & Histamine $\mathrm{H} 1$ receptor & 6 & 60,1 & 9,6 \\
\hline 235 & HRH2 & Histamine $\mathrm{H} 2$ receptor & 4 & 43,9 & 38,5 \\
\hline 236 & HRH3 & Histamine $\mathrm{H} 3$ receptor & 5 & 72,9 & 5,7 \\
\hline 237 & HRH4 & Histamine $\mathrm{H} 4$ receptor & 3 & 51,4 & 12 \\
\hline 238 & HTR1A & 5-hydroxytryptamine receptor $1 \mathrm{~A}$ & 7 & 66,7 & 6,3 \\
\hline 239 & HTR1B & 5-hydroxytryptamine receptor $1 \mathrm{~B}$ & 7 & 75,8 & 2,5 \\
\hline 240 & HTR1D & 5-hydroxytryptamine receptor $1 \mathrm{D}$ & 5 & 66,8 & 4,6 \\
\hline 241 & HTR1F & 5 -hydroxytryptamine receptor $1 \mathrm{~F}$ & 5 & 71,5 & 0,5 \\
\hline 242 & HTR2B & 5-hydroxytryptamine receptor $2 \mathrm{~B}$ & 5 & 61,8 & 6,4 \\
\hline 243 & HTR5A & 5-hydroxytryptamine receptor $5 \mathrm{~A}$ & 4 & 62,6 & 2,9 \\
\hline 244 & OPRK1 & Kappa-type opioid receptor & 7 & 67,6 & 2,9 \\
\hline 245 & OPRL1 & Nociceptin receptor & 5 & 90,3 & 9,7 \\
\hline 246 & PRRP & Prolactin-releasing peptide receptor & 3 & 28,7 & 45 \\
\hline 247 & PTGFR & Prostaglandin F2-alpha receptor & 3 & 49,7 & 21,9 \\
\hline 248 & TAAR3 & Putative trace amine-associated receptor 3 & 4 & 65,6 & 1,2 \\
\hline 249 & TACR2 & Substance-K receptor & 2 & 61,8 & 11 \\
\hline 250 & TM7SF3 & Transmembrane 7 superfamily member 3 & 3 & 58,3 & 3,6 \\
\hline 251 & TM7SF4 & Dendritic cell-specific transmembrane Protein & 3 & 57,7 & 7,2 \\
\hline 252 & HTR2A & 5-hydroxytryptamine receptor $2 \mathrm{~A}$ & 7 & 72 & 1,2 \\
\hline 253 & HTR2B & 5-hydroxytryptamine receptor $2 \mathrm{~B}$ & 5 & 61,8 & 6,4 \\
\hline 254 & HTR2C & 5-hydroxytryptamine receptor $2 \mathrm{C}$ & 5 & 70 & 4,8 \\
\hline 255 & HTR4 & 5-hydroxytryptamine receptor 4 & 8 & 78,5 & 1,4 \\
\hline 256 & HTR5A & 5-hydroxytryptamine receptor $5 \mathrm{~A}$ & 4 & 62,6 & 2,9 \\
\hline 257 & HTR5B & 5-hydroxytryptamine receptor $5 \mathrm{~B}$ & 1 & 55,7 & 19 \\
\hline 258 & HTR6 & 5-hydroxytryptamine receptor 6 & 3 & 69,5 & 5,6 \\
\hline 259 & HTR7 & 5-hydroxytryptamine receptor 7 & 11 & 74,5 & 4,2 \\
\hline 260 & KISS1R & KiSS-1 receptor & 3 & 51 & 26,1 \\
\hline 261 & LGR4 & Leucine rich repeat containing G-protein coupled receptor 4 & 2 & 73,1 & 3,6 \\
\hline 262 & LGR5 & Leucine rich repeat containing G-protein coupled receptor 5 & 8 & 64,2 & 4,6 \\
\hline
\end{tabular}




\begin{tabular}{|c|c|c|c|c|c|}
\hline $\mathbf{N}^{\mathbf{0}}$ & Gene name & Description & Shared tCPs & tCP identity (\%) & Gaps (\%) \\
\hline 263 & LGR6 & Leucine rich repeat containing G-protein coupled receptor 6 & 8 & 64,1 & 10,4 \\
\hline 264 & LHCGR & Lutropin choriogonadotropic hormone receptor & 4 & 63,3 & 7 \\
\hline 265 & LPHN1 & Adhesion $\mathrm{G}$ protein-coupled receptor $\mathrm{L} 1$ & 4 & 56 & 20,3 \\
\hline 266 & LPHN2 & Adhesion G protein-coupled receptor L2 & 9 & 71,7 & 4,8 \\
\hline 267 & LPHN3 & Adhesion $\mathrm{G}$ protein-coupled receptor L3 & 9 & 72,1 & 6,5 \\
\hline 268 & LTB4R & Leukotriene B4 receptor 1 & 5 & 57,6 & 14,9 \\
\hline 269 & LTB4R2 & Leukotriene B4 receptor 2 & 3 & 61,7 & 15 \\
\hline 270 & TMEM185A & Transmembrane protein $185 \mathrm{~A}$ & 7 & 71,5 & 9,2 \\
\hline 271 & TMEM185B & Transmembrane protein $185 \mathrm{~B}$ & 9 & 73 & 0,8 \\
\hline 272 & PAQR5 & Membrane progestin receptor gamma & 4 & 72,8 & 2,6 \\
\hline 273 & PAQR7 & Membrane progestin receptor alpha & 1 & 62,9 & 5,5 \\
\hline 274 & PAQR8 & Membrane progestin receptor beta & 3 & 68,2 & 1,7 \\
\hline 275 & UTS2R & Urotensin-2 receptor & 2 & 52,9 & 14,4 \\
\hline 276 & TAAR1 & Trace amine-associated receptor 1 & 3 & 55,3 & 7,7 \\
\hline 277 & TAAR2 & Trace amine-associated receptor 2 & 3 & 58,4 & 11,3 \\
\hline 278 & TAAR3 & Trace amine-associated receptor 3 & 4 & 65,6 & 1,2 \\
\hline 279 & TAAR5 & Trace amine-associated receptor 5 & 6 & 67,1 & 2,7 \\
\hline 280 & TAAR6 & Trace amine-associated receptor 6 & 7 & 64,8 & 3 \\
\hline 281 & TAAR9 & Trace amine-associated receptor 9 & 5 & 62,9 & 3,6 \\
\hline 282 & ADMR & G-protein coupled receptor 182 & 3 & 59,7 & 11,8 \\
\hline 283 & MAS1 & MAS1 oncogene & 3 & 68 & 2,9 \\
\hline 284 & MC1R & Melanocyte-stimulating hormone receptor & 2 & 59 & 6,3 \\
\hline 285 & $\mathrm{MC} 2 \mathrm{R}$ & Adrenocorticotropic hormone receptor & 3 & 63,4 & 6,2 \\
\hline 286 & MC3R & Melanocortin receptor 3 & 6 & 72 & 3,2 \\
\hline 287 & MC4R & Melanocortin receptor 4 & 7 & 72,4 & 0,6 \\
\hline 288 & MC5R & Melanocortin receptor 5 & 4 & 61,1 & 4 \\
\hline 289 & MRGPRD & Mas-related G-protein coupled receptor D & 1 & 49,1 & 17,8 \\
\hline 290 & MRGPRE & Mas-related G-protein coupled receptor E & 2 & 57,9 & 14,5 \\
\hline 291 & MRGPRF & Mas-related G-protein coupled receptor F & 4 & 63,3 & 8,6 \\
\hline 292 & MRGPRG & Mas-related G-protein coupled receptor G & 0 & 42,5 & 22,3 \\
\hline 293 & MTNR1A & Melatonin receptor type $1 \mathrm{~A}$ & 2 & 40,4 & 33,2 \\
\hline 294 & MTNR1B & Melatonin receptor type 1B & 3 & 56,1 & 13,7 \\
\hline 295 & NMUR1 & Neuromedin-U receptor 1 & 1 & 48,1 & 23,7 \\
\hline 296 & NMUR2 & Neuromedin-U receptor 2 & 1 & 59,7 & 7,2 \\
\hline 297 & NPFF1 & Neuropeptide FF receptor 1 & 7 & 66,7 & 10,7 \\
\hline 298 & NPFF2 & Neuropeptide FF receptor 2 & 6 & 49,9 & 21,5 \\
\hline 299 & NPY1R & Neuropeptide Y receptor type 1 & 1 & 28,3 & 37,4 \\
\hline 300 & NPY2R & Neuropeptide Y receptor type 2 & 3 & 71,3 & 2,9 \\
\hline 301 & NPY5R & Neuropeptide Y receptor type 5 & 4 & 63,2 & 7,1 \\
\hline 302 & NTSR1 & Neurotensin receptor type 1 & 3 & 63,3 & 9,4 \\
\hline 303 & NTSR2 & Neurotensin receptor type 2 & 5 & 63,5 & 11,4 \\
\hline 304 & OPN3 & Opsin-3 & 9 & 66,5 & 4,8 \\
\hline 305 & OPN4 & Opsin-4 & 3 & 57,3 & 17,2 \\
\hline 306 & OPRD1 & Delta-type opioid receptor & 7 & 74,2 & 5,6 \\
\hline 307 & OPRK1 & Kappa-type opioid receptor & 7 & 67,6 & 2,9 \\
\hline 308 & OPRL1 & Nociceptin receptor & 10 & 90,3 & 9,7 \\
\hline 309 & OPRM1 & Mu-type opioid receptor & 2 & 53,9 & 23,7 \\
\hline 310 & OR2B11 & Olfactory receptor 2B11 (Olfr222) & 5 & 64 & 3,2 \\
\hline 311 & $\mathrm{OR} 2 \mathrm{C} 3$ & Olfactory receptor 2C3 (Olfr1389) & 1 & 37 & 33,3 \\
\hline 312 & OR3A1 & Olfactory receptor $3 \mathrm{~A} 1$ (Olfr 10$)$ & 0 & 29,9 & 38,2 \\
\hline 313 & OR3A1 & Olfactory receptor 3A1 (Olfr139) & 1 & 50,3 & 11,9 \\
\hline 314 & OR3A1 & Olfactory receptor 3A1 (Olfr399) & 2 & 52,9 & 12,4 \\
\hline 315 & OR3A1 & Olfactory receptor $3 \mathrm{~A} 1$ (Olfr402) & 4 & 63,9 & 3,7 \\
\hline 316 & OR3A1 & Olfactory receptor $3 \mathrm{~A} 1$ (Olfr410) & 5 & 66,2 & 1,3 \\
\hline 317 & OR3A1 & Olfactory receptor 3A1 (Olfr411) & 2 & 63,8 & 3,9 \\
\hline 318 & OR3A1 & Olfactory receptor 3A1 (Olfr1115) & 1 & 32,7 & 31,1 \\
\hline 319 & OR3A1 & Olfactory receptor 3A1 (Olfr1) & 2 & 33,5 & 39,9 \\
\hline 320 & OR2T8 & Olfactory receptor $2 \mathrm{~T} 8$ (Olfr314) & 2 & 54 & 12,1 \\
\hline 321 & OR2T12 & Olfactory receptor $2 \mathrm{~T} 12$ (Olfr314) & 2 & 54,6 & 8,8 \\
\hline 322 & OR2A14 & Olfactory receptor 2A14 (Olfr444) & 6 & 62,8 & 5,6 \\
\hline 323 & OR2C1 & Olfactory receptor $2 \mathrm{C} 1$ (Olfr15) & 3 & 60,1 & 6,2 \\
\hline 324 & OR13J1 & Olfactory receptor $13 \mathrm{~J} 1$ (Olfr71) & 1 & 67,1 & 2,9 \\
\hline 325 & OR13A1 & Olfactory receptor 13A1 (Olfr211) & 3 & 63 & 10,4 \\
\hline 326 & OR10S1 & Olfactory receptor 10S1 (Olfr982) & 3 & 63 & 6,5 \\
\hline 327 & OR5C1 & Olfactory receptor $5 \mathrm{C} 1$ (Olfr368) & 3 & 63,1 & 7,2 \\
\hline 328 & OR6F1 & Olfactory receptor $6 \mathrm{~F} 1$ (Olfr308) & 1 & 58,7 & 1,9 \\
\hline 329 & OR2Y1 & Olfactory receptor 2Y1 (Olfr1388) & 4 & 62,5 & 6,4 \\
\hline
\end{tabular}




\begin{tabular}{|c|c|c|c|c|c|}
\hline $\mathbf{N}^{\mathbf{0}}$ & Gene name & Description & Shared tCPs & tCP identity (\%) & Gaps (\%) \\
\hline 330 & OR11L1 & Olfactory receptor $11 \mathrm{~L} 1$ (Olfr323) & 4 & 55,3 & 16,9 \\
\hline 331 & OR4D2 & Olfactory receptor 4D1 (Olfr462) & 5 & 67,9 & 3,8 \\
\hline 332 & OR5A1 & Olfactory receptor 5A1 (Olfr76) & 0 & 63,7 & 1,7 \\
\hline 333 & $\mathrm{OR} 2 \mathrm{H} 2$ & Olfactory receptor $2 \mathrm{H} 2$ (Olfr 93$)$ & 6 & 63,6 & 7 \\
\hline 334 & OR10Q1 & Olfactory receptor 10Q1 (Olfr495) & 0 & 27,9 & 44,5 \\
\hline 335 & OR56A4 & Olfactory receptor 5A4 (Olfr684) & 2 & 57,9 & 18 \\
\hline 336 & OR10G3 & Olfactory receptor 10G3 (Olfr1512) & 0 & 63,7 & 0,4 \\
\hline 337 & OR10G2 & Olfactory receptor $10 \mathrm{G} 2(\mathrm{Olfr} 1510)$ & 3 & 69,6 & 3,7 \\
\hline 338 & OR2A5 & Olfactory receptor 2A5 (Olfr448) & 5 & 66,6 & 3,9 \\
\hline 339 & OR2AJ1 & Olfactory receptor 2AJ1 (Olfr170) & 3 & 55,6 & 9,4 \\
\hline 340 & OR2L8 & Olfactory receptor 2L8 (Olfr167) & 3 & 62,1 & 0,9 \\
\hline 341 & OR2L5 & Olfactory receptor 2L5 (Olfr167) & 5 & 60,9 & 2,3 \\
\hline 342 & OR2L2 & Olfactory receptor 2L2 (Olfr167) & 4 & 58,3 & 3,6 \\
\hline 343 & OR2B6 & Olfactory receptor 2B6 (Olfr11) & 4 & 58,8 & 2,1 \\
\hline 344 & OR2W1 & Olfactory receptor $2 \mathrm{~W} 1$ (Olfr263) & 6 & 67,2 & 4,2 \\
\hline 345 & OR2J3 & Olfactory receptor $2 \mathrm{~J} 3$ (Olfr137) & 2 & 57,1 & 3,9 \\
\hline 346 & OR2F2 & Olfactory receptor $2 \mathrm{~F} 2$ (Olfr 453$)$ & 5 & 59,8 & 4,3 \\
\hline 347 & OR2F2 & Olfactory receptor $2 \mathrm{~F} 2$ (Olfr 452$)$ & 7 & 64,7 & 3,9 \\
\hline 348 & OR2F2 & Olfactory receptor $2 \mathrm{~F} 2$ (Olfr 438$)$ & 5 & 64,2 & 3,7 \\
\hline 349 & OR2A25 & Olfactory receptor 2A25 (Olfr447) & 5 & 60,8 & 4,2 \\
\hline 350 & OR2K2 & Olfactory receptor $2 \mathrm{~K} 2$ (Olfr267) & 6 & 69,2 & 1,2 \\
\hline 351 & OR2D2 & Olfactory receptor $2 \mathrm{D} 2$ (Olfr 715$)$ & 2 & 61,5 & 6,1 \\
\hline 352 & OR2D3 & Olfactory receptor 2D3 (Olfr716) & 3 & 59,6 & 7,9 \\
\hline 353 & OR56B1 & Olfactory receptor 56B1 (Olfr657) & 3 & 63 & 5,9 \\
\hline 354 & OR56B1 & Olfactory receptor 56B1 (Olfr504) & 4 & 61,9 & 6,6 \\
\hline 355 & OR52E2 & Olfactory receptor 52E2 (Olfr589) & 2 & 61,3 & 3,5 \\
\hline 356 & OR52A5 & Olfactory receptor 52A5 (Olfr68) & 2 & 59,7 & 3,8 \\
\hline 357 & OR52A5 & Olfactory receptor 52A5 (Olfr69) & 1 & 58,5 & 5,1 \\
\hline 358 & OR52N4 & Olfactory receptor 52N4 (Olfr658) & 3 & 68 & 3,5 \\
\hline 359 & OR52N4 & Olfactory receptor $52 \mathrm{~N} 4$ (Olfr503) & 2 & 64,4 & 3,7 \\
\hline 360 & OR52N5 & Olfactory receptor 52N5 (Olfr669) & 3 & 65,4 & 3,8 \\
\hline 361 & OR52N1 & Olfactory receptor 52N1 (Olfr664) & 1 & 62,2 & 7,6 \\
\hline 362 & OR52E6 & Olfactory receptor 52E6 (Olfr671) & 2 & 63,8 & 5,2 \\
\hline 363 & OR52E6 & Olfactory receptor 52E6 (Olfr675) & 3 & 63,1 & 8,3 \\
\hline 364 & OR52E8 & Olfactory receptor 52E8 (Olfr671) & 2 & 64,9 & 4,4 \\
\hline 365 & OR52E8 & Olfactory receptor 52E8 (Olfr675) & 2 & 63,1 & 5,1 \\
\hline 366 & OR52E4 & Olfactory receptor 52E4 (Olfr677) & 1 & 65,1 & 2,3 \\
\hline 367 & OR51F2 & Olfactory receptor $51 \mathrm{~F} 2$ (Olfr568) & 1 & 62 & 10 \\
\hline 368 & OR51A7 & Olfactory receptor 51A7 (Olfr576) & 5 & 68,7 & 2,7 \\
\hline 369 & OR51A4 & Olfactory receptor 51 A4 (Olfr586) & 1 & 44,8 & 14,3 \\
\hline 370 & OR51A2 & Olfactory receptor 51A2 (Olfr586) & 1 & 44,9 & 14,3 \\
\hline 371 & OR51B4 & Olfactory receptor 51B4 (Olfr66) & 1 & 56,4 & 9,1 \\
\hline 372 & OR51B6 & Olfactory receptor 51B6 (Olfr65) & 2 & 66,4 & 1,2 \\
\hline 373 & OR51M1 & Olfactory receptor $51 \mathrm{M} 1$ (Olfr631) & 1 & 61,3 & 6,1 \\
\hline 374 & OR13G1 & Olfactory receptor 13G1 (Olfr309) & 3 & 63,5 & 4,3 \\
\hline 375 & OR13F1 & Olfactory receptor $13 \mathrm{~F} 1$ (Olfr275) & 4 & 62 & 2,3 \\
\hline 376 & $\mathrm{OR} 13 \mathrm{C} 3$ & Olfactory receptor $13 \mathrm{C} 3$ (Olfr273) & 3 & 59,6 & 13,8 \\
\hline 377 & OR13C8 & Olfactory receptor 13C8 (Olfr272) & 1 & 60,9 & 6,4 \\
\hline 378 & OR13D1 & Olfactory receptor 13D1 (Olfr270) & 3 & 60,1 & 11,8 \\
\hline 379 & OR13H1 & Olfactory receptor $13 \mathrm{H} 1$ (Olfr1235) & 1 & 33 & 28,2 \\
\hline 380 & OR12D3 & Olfactory receptor 12D3 (Olfr109) & 1 & 56,3 & 6,5 \\
\hline 381 & OR11H6 & Olfactory receptor $11 \mathrm{H} 6$ (Olfr745) & 4 & 65,1 & 7,4 \\
\hline 382 & OR11H4 & Olfactory receptor $11 \mathrm{H} 4$ (Olfr747) & 2 & 66,1 & 7 \\
\hline 383 & OR11H4 & Olfactory receptor $11 \mathrm{H} 4$ (Olfr749) & 4 & 66,8 & 6,6 \\
\hline 384 & OR10X1 & Olfactory receptor $10 \mathrm{X} 1$ (Olfr248) & 1 & 61,5 & 1,1 \\
\hline 385 & OR10X1 & Olfactory receptor $10 \mathrm{X} 1$ (Olfr417) & 3 & 65,6 & 1,5 \\
\hline 386 & OR10J5 & Olfactory receptor 10J5 (Olfr16) & 4 & 66,1 & 3,6 \\
\hline 387 & OR10A3 & Olfactory receptor 10A3 (Olfr514) & 1 & 55 & 8,1 \\
\hline 388 & OR10A3 & Olfactory receptor 10A3 (Olfr517) & 0 & 56,4 & 7,1 \\
\hline 389 & OR10A3 & Olfactory receptor 10A3 (Olfr519) & 3 & 58,3 & 3,8 \\
\hline 390 & OR10A3 & Olfactory receptor $10 \mathrm{~A} 3$ (Olfr516) & 4 & 61,4 & 3,3 \\
\hline 391 & OR10A3 & Olfactory receptor $10 \mathrm{~A} 3$ (Olfr512) & 2 & 56,5 & 7,8 \\
\hline 392 & OR10A3 & Olfactory receptor $10 \mathrm{~A} 3$ (Olfr518) & 2 & 57,5 & 10,8 \\
\hline 393 & OR10V1 & Olfactory receptor 10V1 (Olfr420) & 7 & 70,5 & 0,8 \\
\hline 394 & OR9A4 & Olfactory receptor 9A4 (Olfr460) & 5 & 66,2 & 2,4 \\
\hline 395 & OR9A2 & Olfactory receptor 9A2 (Olfr459) & 7 & 63,2 & 8,5 \\
\hline 396 & OR9G4 & Olfactory receptor 9G4 (Olfr1006) & 5 & 65,1 & 5,3 \\
\hline
\end{tabular}




\begin{tabular}{|c|c|c|c|c|c|}
\hline $\mathrm{N}^{\mathbf{0}}$ & Gene name & Description & Shared tCPs & tCP identity (\%) & Gaps (\%) \\
\hline 397 & OR9G4 & Olfactory receptor 9G4 (Olfr1015) & 4 & 58,1 & 9,3 \\
\hline 398 & OR9K2 & Olfactory receptor 9K2 (Olfr825) & 4 & 61,3 & 10,2 \\
\hline 399 & OR9K2 & Olfactory receptor 9K2 (Olfr926) & 0 & 32,5 & 31,7 \\
\hline 400 & OR812 & Olfactory receptor 812 (Olfr1104) & 4 & 62,9 & 1,2 \\
\hline 401 & OR8H3 & Olfactory receptor $8 \mathrm{H} 3$ (Olfr1100) & 3 & 53,7 & 12,3 \\
\hline 402 & OR8H3 & Olfactory receptor 8H3 (Olfr1099) & 1 & 52,1 & 10,9 \\
\hline 403 & OR8H3 & Olfactory receptor 8H3 (Olfr1098) & 2 & 52,1 & 9,4 \\
\hline 404 & OR8H3 & Olfactory receptor 8H3 (Olfr1097) & 2 & 53,4 & 7,3 \\
\hline 405 & OR8J3 & Olfactory receptor 8J3 (Olfr1045) & 3 & 52,8 & 13,8 \\
\hline 406 & OR8H1 & Olfactory receptor $8 \mathrm{H} 1$ (Olfr1100) & 1 & 54,9 & 9,6 \\
\hline 407 & OR8H1 & Olfactory receptor 8H1 (Olfr1099) & 2 & 53,4 & 11 \\
\hline 408 & OR8H1 & Olfactory receptor 8H1 (Olfr1098) & 2 & 53,7 & 9,6 \\
\hline 409 & OR8H1 & Olfactory receptor 8H1 (Olfr1097) & 2 & 62,3 & 3,2 \\
\hline 410 & OR8J1 & Olfactory receptor 8J1 (Olfr1045) & 4 & 59,5 & 2,9 \\
\hline 411 & OR8U1 & Olfactory receptor $8 \mathrm{U} 1$ (Olfr52) & 2 & 63,3 & 4,7 \\
\hline 412 & OR8D4 & Olfactory receptor 8D4 (Olfr895) & 1 & 38,3 & 20,9 \\
\hline 413 & OR8G5 & Olfactory receptor 8G5 (Olfr146) & 1 & 49,6 & 19,9 \\
\hline 414 & OR8G5 & Olfactory receptor 8G5 (Olfr935) & 0 & 54,3 & 15 \\
\hline 415 & OR8G5 & Olfactory receptor 8G5 (Olfr936) & 0 & 43,3 & 27,6 \\
\hline 416 & OR8D2 & Olfactory receptor 8D2 (Olfr924) & 2 & 64,1 & 1,6 \\
\hline 417 & OR8D2 & Olfactory receptor 8D2 (Olfr926) & 2 & 61,4 & 2 \\
\hline 418 & OR8B2 & Olfactory receptor 8B2 (Olfr918) & 2 & 60,5 & 7,5 \\
\hline 419 & OR8B2 & Olfactory receptor 8B2 (Olfr147) & 2 & 63,8 & 4,3 \\
\hline 420 & OR8B3 & Olfactory receptor 8B3 (Olfr918) & 2 & 60,5 & 7,5 \\
\hline 421 & OR8B3 & Olfactory receptor $8 \mathrm{~B} 3$ (Olfr147) & 3 & 72,7 & 7,3 \\
\hline 422 & OR8B4 & Olfactory receptor 8B4 (Olfr878) & 1 & 63,9 & 4,1 \\
\hline 423 & OR7A10 & Olfactory receptor 7A10 (Olfr1353) & 0 & 51,9 & 3,2 \\
\hline 424 & OR7A10 & Olfactory receptor 7A10 (Olfr1352) & 2 & 52,6 & 8,1 \\
\hline 425 & OR7A10 & Olfactory receptor 7A10 (Olfr19) & 0 & 54,5 & 6,3 \\
\hline 426 & OR7A10 & Olfactory receptor 7A10 (Olfr57) & 3 & 55,7 & 12,9 \\
\hline 427 & OR7A10 & Olfactory receptor 7A10 (Olfr 1355) & 0 & 47,1 & 21,4 \\
\hline 428 & OR7A10 & Olfactory receptor 7A10 (Olfr1351) & 2 & 53,5 & 16,2 \\
\hline 429 & OR7A10 & Olfactory receptor 7A10 (Olfr8) & 0 & 46,7 & 21,6 \\
\hline 430 & OR7A10 & Olfactory receptor 7A10 (Olfr 1354) & 0 & 47,2 & 18,8 \\
\hline 431 & OR6K2 & Olfactory receptor $6 \mathrm{~K} 2$ (Olfr420) & 4 & 65,4 & 4,1 \\
\hline 432 & OR6K3 & Olfactory receptor $6 \mathrm{~K} 3$ (Olfr424) & 0 & 53,1 & 11 \\
\hline 433 & OR6K6 & Olfactory receptor $6 \mathrm{~K} 6$ (Olfr231) & 2 & 57,3 & 13 \\
\hline 434 & OR6N2 & Olfactory receptor 6N2 (Olfr231) & 0 & 35,7 & 24,4 \\
\hline 435 & OR6B1 & Olfactory receptor 6B1 (Olfr449) & 4 & 68,1 & 0,6 \\
\hline 436 & OR6C75 & Olfactory receptor 6C75 (Olfr790) & 5 & 69,3 & 3,3 \\
\hline 437 & OR6C2 & Olfactory receptor 6C2 (Olfr791) & 3 & 69,9 & 0 \\
\hline 438 & OR5K1 & Olfactory receptor $5 \mathrm{~K} 1$ (Olfr173) & 5 & 63,1 & 6,5 \\
\hline 439 & OR5K2 & Olfactory receptor $5 \mathrm{~K} 2$ (Olfr173) & 5 & 62,8 & 5,4 \\
\hline 440 & OR5K1 & Olfactory receptor $5 \mathrm{~K} 1$ (Olfr172) & 3 & 63,8 & 1,6 \\
\hline 441 & OR5K2 & Olfactory receptor $5 \mathrm{~K} 2$ (Olfr172) & 5 & 61,4 & 3,7 \\
\hline 442 & OR5P2 & Olfactory receptor 5P2 (Olfr502) & 2 & 57,8 & 12,2 \\
\hline 443 & OR5P2 & Olfactory receptor 5P2 (Olfr506) & 4 & 55,2 & 13,7 \\
\hline 444 & OR5P2 & Olfactory receptor 5P2 (Olfr482) & 2 & 57,2 & 7,8 \\
\hline 445 & OR5P2 & Olfactory receptor 5P2 (Olfr507) & 3 & 57,2 & 12,2 \\
\hline 446 & OR5P2 & Olfactory receptor 5P2 (Olfr483) & 4 & 54,8 & 14,1 \\
\hline 447 & OR5P2 & Olfactory receptor 5P2 (Olfr493) & 1 & 57,4 & 7,8 \\
\hline 448 & OR5P2 & Olfactory receptor 5P2 (Olfr478) & 5 & 59,2 & 9,4 \\
\hline 449 & OR5P2 & Olfactory receptor 5P2 (Olfr497) & 4 & 54 & 12,9 \\
\hline 450 & OR5P2 & Olfactory receptor 5P2 (Olfr469) & 1 & 56,2 & 10,7 \\
\hline 451 & OR5P2 & Olfactory receptor 5P2 (Olfr487) & 2 & 50,2 & 15,6 \\
\hline 452 & OR5P2 & Olfactory receptor 5P2 (Olfr486) & 2 & 49,5 & 15,6 \\
\hline 453 & OR5P2 & Olfactory receptor 5P2 (Olfr510) & 4 & 55,1 & 12,2 \\
\hline 454 & OR5P2 & Olfactory receptor 5P2 (Olfr488) & 4 & 51,3 & 12,2 \\
\hline 455 & OR5P2 & Olfactory receptor 5P2 (Olfr485) & 3 & 52,7 & 14,6 \\
\hline 456 & OR5P2 & Olfactory receptor 5P2 (Olfr492) & 2 & 53,8 & 11,6 \\
\hline 457 & OR5P2 & Olfactory receptor 5P2 (Olfr470) & 2 & 54,9 & 12 \\
\hline 458 & OR5P2 & Olfactory receptor 5P2 (Olfr494) & 4 & 54,4 & 11,3 \\
\hline 459 & OR5P2 & Olfactory receptor 5P2 (Olfr490) & 1 & 52,8 & 10,1 \\
\hline 460 & OR5P2 & Olfactory receptor 5P2 (Olfr484) & 4 & 57,2 & 8,8 \\
\hline 461 & OR5P2 & Olfactory receptor 5P2 (Olfr495) & 4 & 54,2 & 8,8 \\
\hline 462 & OR5P3 & Olfactory receptor $5 \mathrm{P} 3$ (Olfr480) & 1 & 53,5 & 14,5 \\
\hline 463 & OR5P3 & Olfactory receptor 5P3 (Olfr508) & 2 & 59,6 & 7,9 \\
\hline
\end{tabular}




\begin{tabular}{|c|c|c|c|c|c|}
\hline $\mathbf{N}^{\mathbf{0}}$ & Gene name & Description & Shared tCPs & tCP identity (\%) & Gaps (\%) \\
\hline 464 & OR5L1 & Olfactory receptor 5L1 (Olfr1156) & 1 & 52 & 15,9 \\
\hline 465 & OR5L1 & Olfactory receptor 5L1 (Olfr1157) & 1 & 60,9 & 9,9 \\
\hline 466 & OR5L2 & Olfactory receptor 5L2 (Olfr1156) & 1 & 52 & 15,9 \\
\hline 467 & OR5L2 & Olfactory receptor 5L2 (Olfr1157) & 1 & 60,9 & 9,9 \\
\hline 468 & OR5D16 & Olfactory receptor 5D16 (Olfr1155) & 2 & 59,9 & 7,8 \\
\hline 469 & OR5W2 & Olfactory receptor 5W2 (Olfr1152) & 2 & 52,7 & 9 \\
\hline 470 & OR5W2 & Olfactory receptor $5 \mathrm{~W} 2$ (Olfr1153) & 2 & 51,7 & 7,6 \\
\hline 471 & OR5W2 & Olfactory receptor 5W2 (Olfr1140) & 2 & 52,1 & 12,4 \\
\hline 472 & OR5W2 & Olfactory receptor $5 \mathrm{~W} 2$ (Olfr1141) & 3 & 51,7 & 8,5 \\
\hline 473 & OR5W2 & Olfactory receptor 5W2 (Olfr1138) & 3 & 56,7 & 5,5 \\
\hline 474 & OR5W2 & Olfactory receptor 5W2 (Olfr1137) & 0 & 48,4 & 9,8 \\
\hline 475 & OR5W2 & Olfactory receptor 5W2 (Olfr1136) & 1 & 47,6 & 12,3 \\
\hline 476 & OR5W2 & Olfactory receptor 5W2 (Olfr1135) & 1 & 54,1 & 8,2 \\
\hline 477 & OR5I1 & Olfactory receptor 5I1 (Olfr152) & 3 & 59,2 & 6,5 \\
\hline 478 & OR5J2 & Olfactory receptor 5J2 (Olfr1052) & 2 & 55,3 & 7,4 \\
\hline 479 & OR5T2 & Olfactory receptor 5T2 (Olfr1101) & 3 & 49,7 & 19,3 \\
\hline 480 & OR5T2 & Olfactory receptor 5T2 (Olfr1095) & 2 & 48,9 & 16,9 \\
\hline 481 & OR5T2 & Olfactory receptor 5T2 (Olfr1086) & 3 & 50,4 & 17,7 \\
\hline 482 & OR5T2 & Olfactory receptor 5T2 (Olfr141) & 4 & 50,2 & 12,8 \\
\hline 483 & OR5T3 & Olfactory receptor 5T3 (Olfr1093) & 4 & 56,6 & 9 \\
\hline 484 & OR5T1 & Olfactory receptor 5T1 (Olfr1093) & 3 & 56,3 & 3,8 \\
\hline 485 & OR5M9 & Olfactory receptor 5M9 (Olfr1036) & 3 & 62,7 & 3,8 \\
\hline 486 & OR5M9 & Olfactory receptor 5M9 (Olfr1034) & 3 & 63,6 & 2,2 \\
\hline 487 & OR5M3 & Olfactory receptor 5M3 (Olfr1032) & 4 & 66,4 & 1,8 \\
\hline 488 & OR5M3 & Olfactory receptor 5M3 (Olfr1033) & 3 & 66,1 & 9,5 \\
\hline 489 & OR5M8 & Olfactory receptor 5M8 (Olfr1031) & 1 & 58,6 & 10 \\
\hline 490 & OR5M11 & Olfactory receptor 5M11 (Olfr1028) & 3 & 62,9 & 7,6 \\
\hline 491 & OR5M11 & Olfactory receptor 5M11 (Olfr1029) & 2 & 63,4 & 5,2 \\
\hline 492 & OR5M10 & Olfactory receptor $5 \mathrm{M} 10$ (Olfr 1023$)$ & 4 & 62,6 & 5,2 \\
\hline 493 & OR5M10 & Olfactory receptor $5 \mathrm{M} 10$ (Olfr1022) & 6 & 62,7 & 1,7 \\
\hline 494 & OR5AP2 & Olfactory receptor 5AP2 (Olfr1020) & 7 & 62,6 & 5 \\
\hline 495 & OR5AR1 & Olfactory receptor 5AP2 (Olfr1019) & 5 & 71,9 & 0,6 \\
\hline 496 & OR5AK2 & Olfactory receptor 5AK2 (Olfr994) & 0 & 55,5 & 9,3 \\
\hline 497 & OR5AK2 & Olfactory receptor 5AK2 (Olfr995) & 1 & 55,2 & 5,8 \\
\hline 498 & OR5B3 & Olfactory receptor 5B3 (Olfr1461) & 0 & 36,5 & 25,9 \\
\hline 499 & OR5B3 & Olfactory receptor 5B3 (Olfr1458) & 1 & 56,9 & 6,1 \\
\hline 500 & OR5B3 & Olfactory receptor 5B3 (Olfr1467) & 1 & 55,7 & 8,8 \\
\hline 501 & OR5B3 & Olfactory receptor 5B3 (Olfr1469) & 2 & 59,7 & 6,5 \\
\hline 502 & OR5B3 & Olfactory receptor 5B3 (Olfr1459) & 2 & 57,4 & 7,3 \\
\hline 503 & OR5B3 & Olfactory receptor 5B3 (Olfr1462) & 0 & 52,6 & 8,9 \\
\hline 504 & OR5B3 & Olfactory receptor 5B3 (Olfr1446) & 0 & 51,1 & 7,4 \\
\hline 505 & OR5B3 & Olfactory receptor 5B3 (Olfr1453) & 0 & 52,9 & 6,6 \\
\hline 506 & OR5B3 & Olfactory receptor 5B3 (Olfr1447) & 0 & 49,8 & 12 \\
\hline 507 & OR5B3 & Olfactory receptor 5B3 (Olfr1454) & 1 & 54,1 & 8,9 \\
\hline 508 & OR5B3 & Olfactory receptor 5B3 (Olfr1457) & 0 & 54,7 & 7,2 \\
\hline 509 & OR5B3 & Olfactory receptor 5B3 (Olfr1463) & 2 & 52,6 & 7,6 \\
\hline 510 & OR5B2 & Olfactory receptor 5B2 (Olfr1465) & 1 & 55,7 & 5,1 \\
\hline 511 & OR5B2 & Olfactory receptor 5B2 (Olfr1451) & 1 & 57,2 & 6,6 \\
\hline 512 & OR5B12 & Olfactory receptor 5B12 (Olfr1445) & 5 & 62,7 & 1,5 \\
\hline 513 & OR5B12 & Olfactory receptor 5B12 (Olfr1448) & 5 & 62,2 & 3,1 \\
\hline 514 & OR5AN1 & Olfactory receptor 5AN1 (Olfr235) & 0 & 60,3 & 9,9 \\
\hline 515 & OR5AN1 & Olfactory receptor 5AN1 (Olfr1436) & 0 & 56,1 & 7,4 \\
\hline 516 & OR5AN1 & Olfactory receptor 5AN1 (Olfr262) & 2 & 58,8 & 7,1 \\
\hline 517 & OR5AN1 & Olfactory receptor 5AN1 (Olfr1431) & 6 & 58,8 & 9,7 \\
\hline 518 & OR5AN1 & Olfactory receptor 5AN1 (Olfr1434) & 1 & 61,2 & 6,9 \\
\hline 519 & OR5AN1 & Olfactory receptor 5AN1 (Olfr1437) & 1 & 58,7 & 7,5 \\
\hline 520 & OR4F5 & Olfactory receptor 4F5 (Olfr1289) & 3 & 58,5 & 6,3 \\
\hline 521 & OR4F29 & Olfactory receptor 4F29 (Olfr1303) & 1 & 61,9 & 5,8 \\
\hline 522 & OR4F21 & Olfactory receptor 4F21 (Olfr1303) & 2 & 61,8 & 5,8 \\
\hline 523 & OR4B1 & Olfactory receptor 4B1 (Olfr1272) & 1 & 66,6 & 2,7 \\
\hline 524 & OR4B1 & Olfactory receptor 4B1 (Olfr1271) & 1 & 60,2 & 5,5 \\
\hline 525 & OR4B1 & Olfactory receptor 4B1 (Olfr142) & 2 & 63,2 & 5,1 \\
\hline 526 & OR4B1 & Olfactory receptor 4B1 (Olfr1270) & 5 & 65,7 & 5,6 \\
\hline 527 & OR4B1 & Olfactory receptor 4B1 (Olfr32) & 3 & 63,9 & 2,2 \\
\hline 528 & OR4C3 & Olfactory receptor $4 \mathrm{C} 3$ (Olfr1264) & 4 & 59,9 & 11,5 \\
\hline 529 & OR4C5 & Olfactory receptor 4C5 (Olfr1260) & 2 & 52 & 20,6 \\
\hline 530 & OR4A47 & Olfactory receptor 4A47 (Olfr1256) & 3 & 64 & 2,5 \\
\hline
\end{tabular}




\begin{tabular}{|c|c|c|c|c|c|}
\hline $\mathbf{N}^{\mathbf{0}}$ & Gene name & Description & Shared tCPs & tCP identity (\%) & Gaps (\%) \\
\hline 531 & OR4C13 & Olfactory receptor 4C13 (Olfr1258) & 1 & 62,9 & 3,8 \\
\hline 532 & OR4C12 & Olfactory receptor $4 \mathrm{C} 12$ (Olfr1255) & 2 & 65,4 & 3,5 \\
\hline 533 & OR4C12 & Olfactory receptor $4 \mathrm{C} 12$ (Olfr1259) & 8 & 68,3 & 0,6 \\
\hline 534 & OR4C45 & Olfactory receptor $4 \mathrm{C} 45$ (Olfr1262) & 2 & 55,9 & 8,6 \\
\hline 535 & OR4C45 & Olfactory receptor 4C45 (Olfr1263) & 2 & 56,2 & 10,1 \\
\hline 536 & OR4C45 & Olfactory receptor 4C45 (Olfr1261) & 1 & 59,1 & 6,1 \\
\hline 537 & OR4C46 & Olfactory receptor 4C46 (Olfr1258) & 2 & 62,2 & 3,8 \\
\hline 538 & OR4A15 & Olfactory receptor 4A15 (Olfr1234) & 1 & 57,3 & 10 \\
\hline 539 & OR4C15 & Olfactory receptor 4C15 (Olfr1212) & 1 & 49,7 & 21,6 \\
\hline 540 & OR4C15 & Olfactory receptor 4C15 (Olfr1218) & 0 & 45,1 & 25,8 \\
\hline 541 & OR4C15 & Olfactory receptor 4C15 (Olfr1232) & 1 & 46,1 & 23,2 \\
\hline 542 & OR4C15 & Olfactory receptor $4 \mathrm{C} 15$ (Olfr1216) & 1 & 43,1 & 23,6 \\
\hline 543 & OR4C15 & Olfactory receptor 4C15 (Olfr1229) & 1 & 49,7 & 22,8 \\
\hline 544 & OR4C15 & Olfactory receptor $4 \mathrm{C} 15$ (Olfr1214) & 1 & 45 & 26,3 \\
\hline 545 & OR4C15 & Olfactory receptor 4C15 (Olfr1226) & 1 & 49,6 & 22,1 \\
\hline 546 & OR4C15 & Olfactory receptor 4C15 (Olfr1223) & 1 & 47,2 & 26,5 \\
\hline 547 & OR4C15 & Olfactory receptor 4C15 (Olfr1211) & 1 & 53,2 & 18,2 \\
\hline 548 & OR4C15 & Olfactory receptor $4 \mathrm{C} 15$ (Olfr1228) & 1 & 49,5 & 20,6 \\
\hline 549 & OR4C15 & Olfactory receptor 4C15 (Olfr1221) & 0 & 45,9 & 22,8 \\
\hline 550 & OR4C15 & Olfactory receptor $4 \mathrm{C} 15$ (Olfr1215) & 0 & 46,7 & 27,9 \\
\hline 551 & OR4C15 & Olfactory receptor $4 \mathrm{C} 15$ (Olfr1219) & 1 & 48 & 24,9 \\
\hline 552 & OR4C15 & Olfactory receptor 4C15 (Olfr1217) & 0 & 46,9 & 23,8 \\
\hline 553 & OR4C15 & Olfactory receptor 4C15 (Olfr1220) & 1 & 44,8 & 24,2 \\
\hline 554 & OR4C15 & Olfactory receptor 4C15 (Olfr1225) & 0 & 48,3 & 21,9 \\
\hline 555 & OR4C16 & Olfactory receptor 4C16 (Olfr1209) & 5 & 61,6 & 5,6 \\
\hline 556 & OR4C16 & Olfactory receptor 4C16 (Olfr1195) & 4 & 55 & 9,4 \\
\hline 557 & OR4C16 & Olfactory receptor 4C16 (Olfr1199) & 4 & 58,8 & 2,3 \\
\hline 558 & OR4C11 & Olfactory receptor 4C11 (Olfr1205) & 5 & 63,2 & 5,4 \\
\hline 559 & OR4C11 & Olfactory receptor 4C11 (Olfr1201) & 5 & 63,7 & 3,3 \\
\hline 560 & OR4C11 & Olfactory receptor 4C11 (Olfr1206) & 5 & 66,2 & 3,3 \\
\hline 561 & OR4S2 & Olfactory receptor 4S2 (Olfr1193) & 4 & 63,5 & 2,8 \\
\hline 562 & OR4C6 & Olfactory receptor 4C6 (Olfr1189) & 0 & 52,3 & 9,6 \\
\hline 563 & OR4C6 & Olfactory receptor 4C6 (Olfr1230) & 3 & 54,8 & 8,7 \\
\hline 564 & OR4D10 & Olfactory receptor 4D10 (Olfr1426) & 4 & 66 & 5,6 \\
\hline 565 & OR4D10 & Olfactory receptor 4D10 (Olfr1425) & 5 & 68,9 & 2,3 \\
\hline 566 & OR4D10 & Olfactory receptor 4D10 (Olfr1424) & 2 & 65,6 & 3,6 \\
\hline 567 & OR4D5 & Olfactory receptor 4D5 (Olfr984) & 2 & 66,3 & 3,9 \\
\hline 568 & OR4Q3 & Olfactory receptor 4Q3 (Olfr735) & 1 & 53,8 & 16,6 \\
\hline 569 & OR4M1 & Olfactory receptor 4M1 (Olfr734) & 4 & 67,2 & 1,3 \\
\hline 570 & OR4K2 & Olfactory receptor 4K2 (Olfr730) & 2 & 64 & 6,5 \\
\hline 571 & OR4K5 & Olfactory receptor 4K5 (Olfr729) & 4 & 63,2 & 2,8 \\
\hline 572 & OR4K15 & Olfactory receptor 4K15 (Olfr727) & 3 & 64,5 & 10,9 \\
\hline 573 & OR4K15 & Olfactory receptor 4K15 (Olfr726) & 2 & 60,8 & 11,2 \\
\hline 574 & OR4K15 & Olfactory receptor 4K15 (Olfr725) & 4 & 59,9 & 12,2 \\
\hline 575 & OR4L1 & Olfactory receptor 4L1 (Olfr723) & 4 & 61,6 & 3,3 \\
\hline 576 & OR4L1 & Olfactory receptor 4L1 (Olfr724) & 3 & 61 & 3,5 \\
\hline 577 & OR4E2 & Olfactory receptor 4E2 (Olfr1509) & 6 & 68 & 3,7 \\
\hline 578 & OR4M2 & Olfactory receptor 4M2 (Olfr734) & 4 & 64,8 & 1,3 \\
\hline 579 & OR4N4 & Olfactory receptor 4N4 (Olfr733) & 1 & 57,4 & 5,4 \\
\hline 580 & OR4N4 & Olfactory receptor 4N4 (Olfr732) & 1 & 57,9 & 8,6 \\
\hline 581 & OR4F15 & Olfactory receptor 4F15 (Olfr1309) & 2 & 63,5 & 4,7 \\
\hline 582 & OR4F4 & Olfactory receptor 4F4 (Olfr1289) & 3 & 59,5 & 3,8 \\
\hline 583 & OR1S1 & Olfactory receptor 1S1 (Olfr1496) & 0 & 28,9 & 35 \\
\hline 584 & OR1A2 & Olfactory receptor $1 \mathrm{~A} 2$ (Olfr 43$)$ & 2 & 58,6 & 4 \\
\hline 585 & OR1A2 & Olfactory receptor 1A2 (Olfr403) & 3 & 58,6 & 4,2 \\
\hline 586 & OR1A1 & Olfactory receptor $1 \mathrm{~A} 1$ (Olfr 43$)$ & 3 & 63,8 & 3,8 \\
\hline 587 & OR1A1 & Olfactory receptor 1A1 (Olfr403) & 3 & 63,4 & 5,6 \\
\hline 588 & OR8G1 & Olfactory receptor 8G1 (Olfr27) & 2 & 53,1 & 5,8 \\
\hline 589 & OR8G1 & Olfactory receptor 8G1 (Olfr948) & 2 & 51,4 & 11,5 \\
\hline 590 & OR8G1 & Olfactory receptor $8 \mathrm{G} 1$ (Olfr 44$)$ & 1 & 59,1 & 8,3 \\
\hline 591 & OR8G1 & Olfactory receptor 8G1 (Olfr945) & 1 & 52,7 & 12,7 \\
\hline 592 & OR8G1 & Olfactory receptor 8G1 (Olfr937) & 1 & 57,9 & 7,4 \\
\hline 593 & OR8G1 & Olfactory receptor 8G1 (Olfr951) & 1 & 53,2 & 11 \\
\hline 594 & OR8G1 & Olfactory receptor 8G1 (Olfr954) & 2 & 53,9 & 7,5 \\
\hline 595 & OR8G1 & Olfactory receptor 8G1 (Olfr943) & 0 & 52,3 & 10,4 \\
\hline 596 & OR8G1 & Olfactory receptor 8G1 (Olfr1537) & 1 & 54 & 7,1 \\
\hline 597 & OR8G1 & Olfactory receptor 8G1 (Olfr944) & 1 & 53,1 & 7,7 \\
\hline
\end{tabular}




\begin{tabular}{|c|c|c|c|c|c|}
\hline $\mathbf{N}^{\mathbf{0}}$ & Gene name & Description & Shared tCPs & tCP identity (\%) & Gaps (\%) \\
\hline 598 & OR1J1 & Olfactory receptor $1 \mathrm{~J} 1$ (Olfr3) & 3 & 61 & 8,1 \\
\hline 599 & OR6Q1 & Olfactory receptor 6Q1 (Olfr522) & 0 & 28,8 & 35,8 \\
\hline 600 & OR6C1 & Olfactory receptor $6 \mathrm{C} 1$ (Olfr802) & 5 & 65 & 0 \\
\hline 601 & OR6C1 & Olfactory receptor $6 \mathrm{C} 1$ (Olfr786) & 2 & 65,5 & 0 \\
\hline 602 & OR2L13 & Olfactory receptor 2L13 (Olfr166) & 3 & 57,5 & 3,6 \\
\hline 603 & OR2L13 & Olfactory receptor 2L13 (Olfr168) & 2 & 57,9 & 3,2 \\
\hline 604 & OR5B21 & Olfactory receptor 5B21 (Olfr1444) & 4 & 63,5 & 4,4 \\
\hline 605 & OR5D18 & Olfactory receptor 5D18 (Olfr1161) & 2 & 53,7 & 12 \\
\hline 606 & OR5D18 & Olfactory receptor 5D18 (Olfr73) & 2 & 58,4 & 5,6 \\
\hline 607 & OR5D18 & Olfactory receptor 5D18 (Olfr74) & 2 & 58,2 & 7,6 \\
\hline 608 & OR51I2 & Olfactory receptor 5112 (Olfr641) & 4 & 73,2 & 0 \\
\hline 609 & OR52D1 & Olfactory receptor 52D1 (Olfr557) & 0 & 31,8 & 38,2 \\
\hline 610 & OR1J4 & Olfactory receptor $1 \mathrm{~J} 4$ (Olfr350) & 1 & 66,4 & 3,9 \\
\hline 611 & OR1N1 & Olfactory receptor $1 \mathrm{~N} 1$ (Olfr353) & 3 & 61,4 & 4,8 \\
\hline 612 & OR1N1 & Olfactory receptor $1 \mathrm{~N} 1$ (Olfr351) & 1 & 62,8 & 3,7 \\
\hline 613 & OR2A2 & Olfactory receptor 2A2 (Olfr437) & 1 & 55,9 & 10,5 \\
\hline 614 & OR10K2 & Olfactory receptor 10K2 (Olfr370) & 4 & 58,8 & 5,8 \\
\hline 615 & OR2T4 & Olfactory receptor 2T4 (Olfr328) & 2 & 55,7 & 13,8 \\
\hline 616 & OR2T4 & Olfactory receptor $2 \mathrm{~T} 4$ (Olfr331) & 2 & 57,3 & 12,8 \\
\hline 617 & OR2T4 & Olfactory receptor $2 \mathrm{~T} 4$ (Olfr224) & 2 & 55,1 & 13,9 \\
\hline 618 & OR2T4 & Olfactory receptor $2 \mathrm{~T} 4$ (Olfr325) & 2 & 56,1 & 14,7 \\
\hline 619 & OR10A5 & Olfactory receptor 10A5 (Olfr713) & 7 & 74,3 & 2,2 \\
\hline 620 & OR10A5 & Olfactory receptor 10A5 (Olfr714) & 5 & 72,2 & 0 \\
\hline 621 & OR6N1 & Olfactory receptor 6N1 (Olfr429) & 2 & 68,3 & 1,9 \\
\hline 622 & OR9G1 & Olfactory receptor 9G1 (Olfr1014) & 4 & 57,7 & 7 \\
\hline 623 & OR9G1 & Olfactory receptor 9G1 (Olfr1016) & 4 & 54,9 & 8,7 \\
\hline 624 & OR1N2 & Olfactory receptor $1 \mathrm{~N} 2$ (Olfr354) & 4 & 66,5 & 5,7 \\
\hline 625 & OR2J1 & Olfactory receptor $2 \mathrm{~J} 1$ (Olfr137) & 3 & 57,1 & 3,8 \\
\hline 626 & OR6C74 & Olfactory receptor 6C74 (Olfr821) & 3 & 70,8 & 1,5 \\
\hline 627 & OR9I1 & Olfactory receptor 9I1 (Olfr1499) & 1 & 54,9 & 11 \\
\hline 628 & OR9I1 & Olfactory receptor $9 \mathrm{I1}$ (Olfr1502) & 1 & 56,6 & 6,1 \\
\hline 629 & OR9I1 & Olfactory receptor 9I1 (Olfr1505) & 1 & 56,2 & 7,5 \\
\hline 630 & OR7G2 & Olfactory receptor 7G2 (Olfr855) & 1 & 47,2 & 14,7 \\
\hline 631 & OR7G2 & Olfactory receptor 7G2 (Olfr830) & 2 & 44,1 & 19,2 \\
\hline 632 & OR7G2 & Olfactory receptor 7G2 (Olfr835) & 0 & 43,1 & 18,6 \\
\hline 633 & OR7G2 & Olfactory receptor 7G2 (Olfr828) & 1 & 44,8 & 17,8 \\
\hline 634 & OR7G2 & Olfactory receptor 7G2 (Olfr843) & 1 & 41,8 & 15,8 \\
\hline 635 & OR7G2 & Olfactory receptor 7G2 (Olfr850) & 3 & 47,8 & 19,2 \\
\hline 636 & OR7G2 & Olfactory receptor 7G2 (Olfr829) & 1 & 44,5 & 21,1 \\
\hline 637 & OR7G2 & Olfactory receptor 7G2 (Olfr854) & 3 & 50,2 & 18,3 \\
\hline 638 & OR7G2 & Olfactory receptor 7G2 (Olfr849) & 2 & 43,3 & 14,9 \\
\hline 639 & OR7G2 & Olfactory receptor 7G2 (Olfr837) & 2 & 42,7 & 20,1 \\
\hline 640 & OR7G2 & Olfactory receptor 7G2 (Olfr851) & 0 & 41,2 & 20,3 \\
\hline 641 & OR7G2 & Olfactory receptor 7G2 (Olfr846) & 3 & 43,3 & 18,2 \\
\hline 642 & OR7G2 & Olfactory receptor 7G2 (Olfr836) & 2 & 44,8 & 20,3 \\
\hline 643 & OR7G2 & Olfactory receptor 7G2 (Olfr847) & 4 & 42,8 & 19,5 \\
\hline 644 & OR7G2 & Olfactory receptor 7G2 (Olfr845) & 1 & 46,6 & 15,4 \\
\hline 645 & OR7A17 & Olfactory receptor 7A17 (Olfr1353) & 1 & 53,2 & 10,4 \\
\hline 646 & OR7A17 & Olfactory receptor 7A17 (Olfr1352) & 0 & 51,6 & 9,6 \\
\hline 647 & OR7A17 & Olfactory receptor 7A17 (Olfr19) & 1 & 56,4 & 2,3 \\
\hline 648 & OR7A17 & Olfactory receptor 7A17 (Olfr57) & 1 & 57,7 & 14,4 \\
\hline 649 & OR7A17 & Olfactory receptor 7A17 (Olfr1355) & 0 & 46,8 & 16,5 \\
\hline 650 & OR7A17 & Olfactory receptor 7A17 (Olfr1351) & 0 & 55,1 & 15,8 \\
\hline 651 & OR7A17 & Olfactory receptor 7A17 (Olfr8) & 1 & 45,2 & 21,2 \\
\hline 652 & OR7A17 & Olfactory receptor 7A17 (Olfr1354) & 0 & 45,8 & 20,9 \\
\hline 653 & OR8D1 & Olfactory receptor 8D1 (Olfr26) & 3 & 64,7 & 5,3 \\
\hline 654 & OR8D1 & Olfactory receptor 8D1 (Olfr933) & 2 & 63 & 5,7 \\
\hline 655 & OR8D1 & Olfactory receptor 8D1 (Olfr930) & 2 & 62,4 & 4 \\
\hline 656 & OR2AG1 & Olfactory receptor 2AG1 (Olfr701) & 1 & 62,5 & 3,3 \\
\hline 657 & OR2AG1 & Olfactory receptor 2AG1 (Olfr706) & 3 & 61 & 5,9 \\
\hline 658 & OR6Y1 & Olfactory receptor 6Y1 A5 (Olfr220) & 5 & 64,2 & 3,6 \\
\hline 659 & OR1S2 & Olfactory receptor 1S2 (Olfr1496) & 2 & 59,3 & 8,2 \\
\hline 660 & OR6C76 & Olfactory receptor 6C76 (Olfr809) & 3 & 62,1 & 11 \\
\hline 661 & OR6C76 & Olfactory receptor 6C76 (Olfr813) & 4 & 65,5 & 4,2 \\
\hline 662 & OR8K5 & Olfactory receptor 8K5 (Olfr1008) & 1 & 55,6 & 7 \\
\hline 663 & OR8K5 & Olfactory receptor $8 \mathrm{~K} 5$ (Olfr1053) & 2 & 58,6 & 6 \\
\hline 664 & OR8K5 & Olfactory receptor 8K5 (Olfr1051) & 1 & 57,4 & 1,8 \\
\hline
\end{tabular}




\begin{tabular}{|c|c|c|c|c|c|}
\hline $\mathrm{N}^{\mathbf{0}}$ & Gene name & Description & Shared tCPs & tCP identity (\%) & Gaps (\%) \\
\hline 665 & OR8K5 & Olfactory receptor 8K5 (Olfr1049) & 0 & 56,8 & 2 \\
\hline 666 & OR8K5 & Olfactory receptor 8K5 (Olfr1048) & 3 & 52 & 9,8 \\
\hline 667 & OR1L6 & Olfactory receptor 1L6 (Olfr365) & 1 & 64,3 & 4,5 \\
\hline 668 & OR2F1 & Olfactory receptor $2 \mathrm{~F} 1$ (Olfr452) & 7 & 64 & 6,7 \\
\hline 669 & OR2F1 & Olfactory receptor $2 \mathrm{~F} 1$ (Olfr38) & 8 & 66,7 & 5,5 \\
\hline 670 & OR2F1 & Olfactory receptor $2 \mathrm{~F} 1$ (Olfr453) & 5 & 62,7 & 2,7 \\
\hline 671 & OR4N5 & Olfactory receptor 4N5 (Olfr722) & 0 & 29,5 & 41,2 \\
\hline 672 & OR4D6 & Olfactory receptor 4D6 (Olfr1428) & 5 & 65,4 & 1,9 \\
\hline 673 & OR1L4 & Olfactory receptor 1L4 (Olfr365) & 2 & 65,3 & 5,5 \\
\hline 674 & OR6X1 & Olfactory receptor $6 \mathrm{X} 1$ (Olfr986) & 5 & 66,9 & 1,7 \\
\hline 675 & OR52I1 & Olfactory receptor 52I1 (Olfr640) & 0 & 27 & 42,4 \\
\hline 676 & OR51T1 & Olfactory receptor $51 \mathrm{~T} 1$ (Olfr574) & 0 & 54,4 & 14,5 \\
\hline 677 & OR9Q1 & Olfactory receptor 9Q1 (Olfr1500) & 4 & 65 & 0,7 \\
\hline 678 & OR52B4 & Olfactory receptor 52B4 (Olfr547) & 6 & 66,9 & 3 \\
\hline 679 & OR52I2 & Olfactory receptor $52 \mathrm{I} 2$ (Olfr556) & 0 & 55,9 & 10,8 \\
\hline 680 & OR6C3 & Olfactory receptor $6 \mathrm{C} 3$ (Olfr788) & 4 & 68,8 & 3 \\
\hline 681 & OR6C6 & Olfactory receptor 6C6 (Olfr779) & 2 & 64,8 & 3,1 \\
\hline 682 & OR6C6 & Olfactory receptor 6C6 (Olfr782) & 2 & 65,8 & 0,8 \\
\hline 683 & OR6C6 & Olfactory receptor 6C6 (Olfr804) & 2 & 66,2 & 0 \\
\hline 684 & OR52H1 & Olfactory receptor 52H1 (Olfr648) & 4 & 65,5 & 7,7 \\
\hline 685 & OR52L1 & Olfactory receptor 52L1 (Olfr685) & 2 & 63,6 & 5,1 \\
\hline 686 & OR7G3 & Olfactory receptor 7G3 (Olfr834) & 2 & 51,1 & 5,6 \\
\hline 687 & OR5AS1 & Olfactory receptor $5 \mathrm{AS} 1$ (Olfr1111) & 2 & 56,3 & 10,3 \\
\hline 688 & OR5AC2 & Olfactory receptor 5AC2 (Olfr202) & 3 & 52,5 & 9,7 \\
\hline 689 & OR5AC2 & Olfactory receptor 5AC2 (Olfr198) & 2 & 49,2 & 15,9 \\
\hline 690 & OR5AC2 & Olfactory receptor 5AC2 (Olfr201) & 2 & 47,1 & 19,6 \\
\hline 691 & OR5AC2 & Olfactory receptor 5AC2 (Olfr199) & 3 & 47,2 & 17,1 \\
\hline 692 & OR2A12 & Olfactory receptor 2A12 (Olfr446) & 4 & 58,5 & 7,5 \\
\hline 693 & OR7A5 & Olfactory receptor 7A5 (Olfr1352) & 1 & 46,4 & 21,4 \\
\hline 694 & OR7A5 & Olfactory receptor 7A5 (Olfr19) & 0 & 53,9 & 9,7 \\
\hline 695 & OR7A5 & Olfactory receptor 7A5 (Olfr57) & 1 & 54,2 & 14 \\
\hline 696 & OR7A5 & Olfactory receptor 7A5 (Olfr1355) & 1 & 46,9 & 20,3 \\
\hline 697 & OR7A5 & Olfactory receptor 7A5 (Olfr1351) & 3 & 54,6 & 12 \\
\hline 698 & OR7A5 & Olfactory receptor 7A5 (Olfr8) & 1 & 46,9 & 19,4 \\
\hline 699 & OR7A5 & Olfactory receptor 7A5 (Olfr1354) & 1 & 46,9 & 19,1 \\
\hline 700 & OR5M1 & Olfactory receptor 5M1 (Olfr1023) & 4 & 62,9 & 5,6 \\
\hline 701 & OR5M1 & Olfactory receptor 5M1 (Olfr1022) & 6 & 63,2 & 1,9 \\
\hline 702 & $\mathrm{OR} 8 \mathrm{H} 2$ & Olfactory receptor $8 \mathrm{H} 2$ (Olfr1100) & 2 & 54,1 & 11,6 \\
\hline 703 & OR8H2 & Olfactory receptor 8H2 (Olfr1099) & 1 & 52,5 & 8 \\
\hline 704 & OR8H2 & Olfactory receptor 8H2 (Olfr1098) & 2 & 53,5 & 9,8 \\
\hline 705 & OR8H2 & Olfactory receptor 8H2 (Olfr1097) & 2 & 53,9 & 7,9 \\
\hline 706 & OR5D14 & Olfactory receptor 5D14 (Olfr1163) & 2 & 52,8 & 8,2 \\
\hline 707 & OR5D14 & Olfactory receptor 5D14 (Olfr1162) & 3 & 54,8 & 6,8 \\
\hline 708 & OR5D14 & Olfactory receptor 5D14 (Olfr868) & 0 & 31,1 & 32,5 \\
\hline 709 & OR7E24 & Olfactory receptor 7E24 (Olfr873) & 2 & 53,2 & 13,1 \\
\hline 710 & OR7E24 & Olfactory receptor 7E24 (Olfr866) & 3 & 47,4 & 14,5 \\
\hline 711 & OR7E24 & Olfactory receptor 7E24 (Olfr869) & 1 & 50,3 & 12,6 \\
\hline 712 & OR7E24 & Olfactory receptor 7E24 (Olfr872) & 2 & 49,3 & 15,8 \\
\hline 713 & OR52J3 & Olfactory receptor $52 \mathrm{~J} 3$ (Olfr592) & 3 & 61,2 & 4,5 \\
\hline 714 & OXTR & Oxytocin receptor & 6 & 69,2 & 9,2 \\
\hline 715 & P2RY1 & P2Y purinoceptor 1 & 7 & 69,7 & 1,1 \\
\hline 716 & P2RY10 & Putative $\mathrm{P} 2 \mathrm{Y}$ purinoceptor 10 & 1 & 47,2 & 23 \\
\hline 717 & P2RY12 & $\mathrm{P} 2 \mathrm{Y}$ purinoceptor 12 & 2 & 60,9 & 5,2 \\
\hline 718 & P2RY4 & $\mathrm{P} 2 \mathrm{Y}$ purinoceptor 4 & 2 & 63,7 & 6,4 \\
\hline 719 & P2RY5 & Lysophosphatidic acid receptor 6 & 3 & 70,2 & 1,7 \\
\hline 720 & P2RY6 & $\mathrm{P} 2 \mathrm{Y}$ purinoceptor 6 & 1 & 63 & 5 \\
\hline 721 & PPYR1 & Neuropeptide Y receptor type 4 & 0 & 56,3 & 9,9 \\
\hline 722 & PTAFR & Platelet-activating factor receptor & 0 & 57,9 & 13,6 \\
\hline 723 & PTGDR & Prostaglandin D2 receptor 2 & 3 & 55,6 & 11,9 \\
\hline 724 & PTGER1 & Prostaglandin E2 receptor EP1 subtype & 2 & 58,9 & 8,3 \\
\hline 725 & PTGER2 & Prostaglandin E2 receptor EP2 subtype & 8 & 65,3 & 2,6 \\
\hline 726 & PTGER3 & Prostaglandin E2 receptor EP3 subtype & 6 & 58,6 & 16,5 \\
\hline 727 & PTGER4 & Prostaglandin E2 receptor EP4 subtype & 5 & 68,7 & 7,4 \\
\hline 728 & PTGFR & Prostaglandin F2-alpha receptor & 2 & 49,7 & 21,9 \\
\hline 729 & PTGIR & Prostacyclin receptor & 4 & 55,6 & 16,5 \\
\hline 730 & PTHR1 & Parathyroid hormone/parathyroid & 6 & 69,3 & 5,5 \\
\hline 731 & PTHR2 & Parathyroid hormone 2 receptor & 6 & 64 & 4,9 \\
\hline
\end{tabular}




\begin{tabular}{|c|c|c|c|c|c|}
\hline $\mathbf{N}^{\mathbf{0}}$ & Gene name & Description & Shared tCPs & tCP identity (\%) & Gaps (\%) \\
\hline 732 & RRH & Visual pigment-like receptor peropsin & 2 & 61,4 & 5,8 \\
\hline 733 & RLN3R1 & Relaxin-3 receptor 1 & 5 & 65,7 & 4,1 \\
\hline 734 & SCTR & Secretin receptor & 5 & 64,5 & 8 \\
\hline 735 & SMO & Smoothened homolog & 5 & 75,6 & 31,7 \\
\hline 736 & SSTR1 & Somatostatin receptor type 1 & 7 & 73,1 & 3,7 \\
\hline 737 & SSTR2 & Somatostatin receptor type 2 & 5 & 71,6 & 5,6 \\
\hline 738 & SSTR3 & Somatostatin receptor type 3 & 5 & 61,7 & 11,3 \\
\hline 739 & SSTR4 & Somatostatin receptor type 4 & 4 & 65 & 7,5 \\
\hline 740 & SSTR5 & Somatostatin receptor type 5 & 1 & 50,4 & 19,9 \\
\hline 741 & TACR1 & Substance-P receptor & 6 & 75,9 & 1,8 \\
\hline 742 & TACR2 & Substance-K receptor & 2 & 61,8 & 11 \\
\hline 743 & TACR3 & Neuromedin-K receptor & 6 & 67,4 & 7,2 \\
\hline 744 & TRHR & Thyrotropin-releasing hormone receptor & 6 & 76,1 & 2,6 \\
\hline 745 & TSHR & Thyrotropin receptor & 6 & 68,2 & 3,3 \\
\hline
\end{tabular}

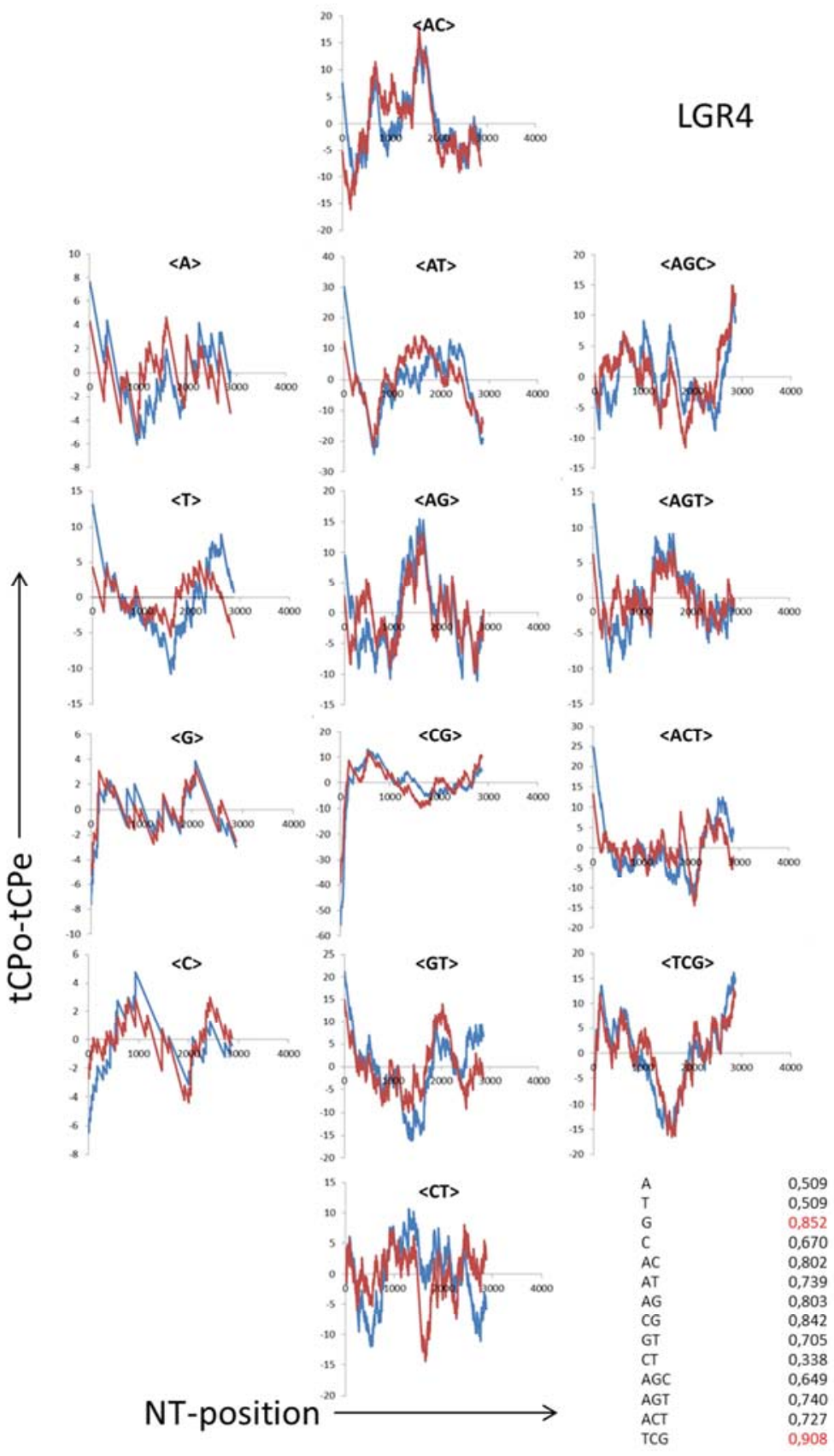

Figure 8. Comparison of tCP-profiles from the human-mouse ortholog LGR4. Red and blue lines correspond to the profiles of mouse and human, respectively. The insets display the name of the ortholog (upper right corner), and a table with the Pearson correlation coefficient, $r$, between $t C P$-profiles of human and mouse (lower right corner). Pearson correlation coefficient for $r \geq 0.85$ are in red. 


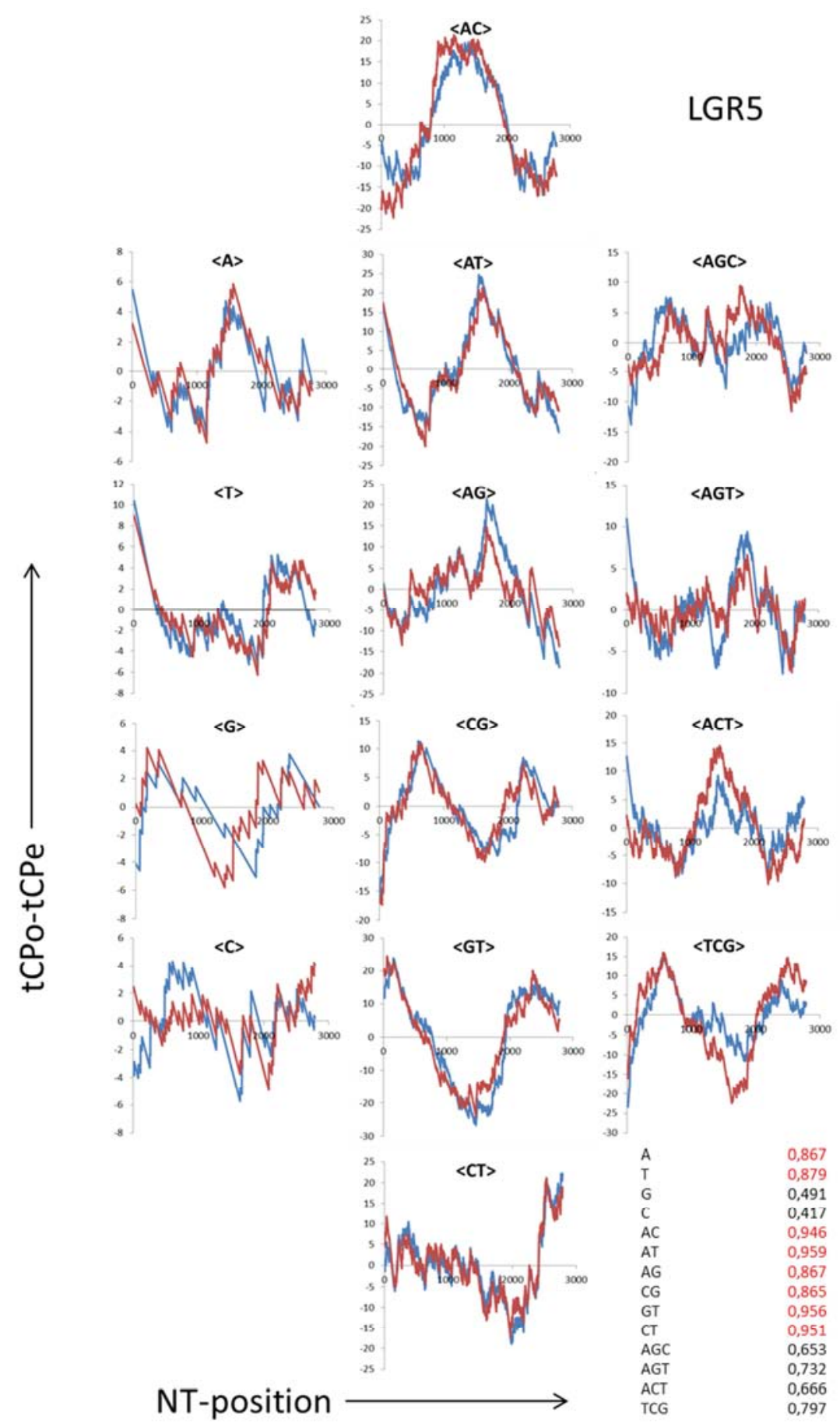

Figure 9. Comparison of tCP-profiles from the human-mouse ortholog LGR4. Red and blue lines correspond to the profiles of mouse and human, respectively. The insets display the name of the ortholog (upper right corner), and a table with the Pearson correlation coefficient, $r$, between $t C P$-profiles of human and mouse (lower right corner). Pearson correlation coefficient for $r \geq 0.85$ are in red.

\section{Data Accessibility Statement}

Materials, data and associated protocols are promptly available to readers without undue qualification in material transfer agreement.

\section{Competing Interests}

The authors declare that they have no competing interests.

\section{Acknowledgements}

I would like to express my deep gratitude to Prof Carlos Alonso Bedate who died on April 13, 2020 in the middle of the SARS CoV-2 pandemic for his advice, guidance, friendship and encouragement throughout the last twenty-five years of my life. An institutional grant from Foundation Ramón Areces is also acknowledged. 


\section{References}

[1] R. Fredriksson, M. C. Lagerstrom, L. G. Lundin, H. B. Schioth, The G-protein-coupled receptors in the human genome form five main families. Phylogenetic analysis, paralogon groups, and fingerprints. Mol Pharmacol 63, 12561272 (2003).

[2] D. M. Rosenbaum, S. G. Rasmussen, B. K. Kobilka, The structure and function of G-protein-coupled receptors. Nature 459, 356-363 (2009).

[3] M. Rask-Andersen, M. S. Almén, H. B. Schiöth. Trends in the exploitation of novel drug targets. Nat Rev Drug Discov 10, 579-590 (2011).

[4] O. S. Soyer, M. W. Dimmic, R. R. Neubig, R. A. Goldstein. Dimerization in aminergic G-protein-coupled receptors: application of a hidden-site class model of evolution. Biochemistry 42,14522-14531 (2003).

[5] W. K. Kroeze, D. J. Sheffler, B. L. Roth, G-protein-coupled receptors at a glance. J Cell Sci 116, 4867-4869 (2003).

[6] Y. Zhang, M. E. Devries, J. Skolnick, Structure modeling of all identified $G$ protein-coupled receptors in the human genome. PLoS Comput Biol 2, e13 (2006).

[7] E. van der Horst, J. E. Peironcely, A. P. Ijzerman, M. W. Beukers, J. R. Lane, H. W. van Vlijmen, M. T. Emmerich, Y. Okuno, A. Bender, A novel chemogenomics analysis of $\mathrm{G}$ protein-coupled receptors (GPCRs) and their ligands: a potential strategy for receptor de-orphanization. BMC Bioinformatics 11, 316 (2010).

[8] E. Jacoby, R. Bouhelal, M. Gerspacher, K. Seuwen. The 7 TM G-protein-coupled receptor target family. ChemMedChem 1, 761-782 (2006).

[9] Y. Kawasawa, L. M. McKenzie, D. P. Hill, H. Bono, M. Yanagisawa, RIKEN GER Group; GSL Members, G proteincoupled receptor genes in the FANTOM2 database. Genome Res 13, 1466-1477 (2003).

[10] M. Wistrand, L. Kall, E. L. Sonnhammer. A general model of $\mathrm{G}$ protein-coupled receptor sequences and its application to detect remote homologs. Protein Sci 15, 509-521 (1991).

[11] Buck. L, Axel. R. A novel multigene family may encode odorant receptors: a molecular basis for odor recognition. Cell 65, 175-187 (2006).

[12] Y. Pilpel, D. Lancet. The variable and conserved interfaces of modeled olfactory receptor proteins. Protein Sci 8, 969-977 (1999).

[13] W. C. Probst, L. A. Snyder, D. I. Schuster, J. Brosius, S. C. Sealfon. Sequence alignment of the G-protein coupled receptor superfamily. DNA Cell Biol 11, 1-20 (1992).

[14] R. A. Gibbs, G. M. Weinstock, M. L. Metzker, D. M. Muzny, E. J. Sodergren, S. Scherer, G. Scott, D. Steffen, K. C. Worley, P. E. Burch, G. Okwuonu, S. Hines, L. Lewis, C. DeRamo, O. Delgado, S. Dugan-Rocha, G. Miner, M. Morgan, A. Hawes, R. Gill, Celera, R. A. Holt, M. D. Adams, P. G. Amanatides, H. Baden-Tillson, M. Barnstead, S. Chin, C. A. Evans, S. Ferriera, C. Fosler, A. Glodek, Z. Gu, D. Jennings, C. L. Kraft, T. Nguyen, C. M. Pfannkoch, C. Sitter, G. G. Sutton, J. C. Venter, T. Woodage, D. Smith, H. M. Lee, E. Gustafson, P.
Cahill, A. Kana, L. Doucette-Stamm, K. Weinstock, K. Fechtel, R. B. Weiss, D. M. Dunn, E. D. Green, R. W. Blakesley, G. G. Bouffard, P. J. De Jong, K. Osoegawa, B. Zhu, M. Marra, J. Schein, I. Bosdet, C. Fjell, S. Jones, M. Krzywinski, C. Mathewson, A. Siddiqui, N. Wye, J. McPherson, S. Zhao, C. M. Fraser, J. Shetty, S. Shatsman, K. Geer, Y. Chen, S. Abramzon, W. C. Nierman, P. H. Havlak, R. Chen, K. J. Durbin, A. Egan, Y. Ren, X. Z. Song, B. Li, Y. Liu, X. Qin, S. Cawley, K. C. Worley, A. J. Cooney, L. M. D'Souza, K. Martin, J. Q. Wu, M. L. Gonzalez-Garay, A. R. Jackson, K. J. Kalafus, M. P. McLeod, A. Milosavljevic, D. Virk, A. Volkov, D. A. Wheeler, Z. Zhang, J. A. Bailey, E. E. Eichler, E. Tuzun, E. Birney, E. Mongin, A. Ureta-Vidal, C. Woodwark, E. Zdobnov, P. Bork, M. Suyama, D. Torrents, M. Alexandersson, B. J. Trask, J. M. Young, H. Huang, H. Wang, H. Xing, S. Daniels, D. Gietzen, J. Schmidt, K. Stevens, U. Vitt, J. Wingrove, F. Camara, M. Mar Alba, J. F. Abril, R. Guigo, A. Smit, I. Dubchak, E. M. Rubin, O. Couronne, A. Poliakov, N. Hubner, D. Ganten, C. Goesele, O. Hummel, T. Kreitler, Y. A. Lee, J. Monti, H. Schulz, H. Zimdahl, H. Himmelbauer, H. Lehrach, H. J. Jacob, S. Bromberg, J. Gullings-Handley, M. I. Jensen-Seaman, A. E. Kwitek, J. Lazar, D. Pasko, P. J. Tonellato, S. Twigger, C. P. Ponting, J. M. Duarte, S. Rice, L. Goodstadt, S. A. Beatson, R. D. Emes, E. E. Winter, C. Webber, P. Brandt, G. Nyakatura, M. Adetobi, F. Chiaromonte, L. Elnitski, P. Eswara, R. C. Hardison, M. Hou, D. Kolbe, K. Makova, W. Miller, A. Nekrutenko, C. Riemer, S. Schwartz, J. Taylor, S. Yang, Y. Zhang, K. Lindpaintner, T. D. Andrews, M. Caccamo, M. Clamp, L. Clarke, V. Curwen, R. Durbin, E. Eyras, S. M. Searle, G. M. Cooper, S. Batzoglou, M. Brudno, A. Sidow, E. A. Stone, J. C. Venter, B. A. Payseur, G. Bourque, C. Lopez-Otin, X. S. Puente, K. Chakrabarti, S. Chatterji, C. Dewey, L. Pachter, N. Bray, V. B. Yap, A. Caspi, G. Tesler, P. A. Pevzner, D. Haussler, K. M. Roskin, R. Baertsch, H. Clawson, T. S. Furey, A. S. Hinrichs, D. Karolchik, W. J. Kent, K. R. Rosenbloom, H. Trumbower, M. Weirauch, D. N. Cooper, P. D. Stenson, B. Ma, M. Brent, M. Arumugam, D. Shteynberg, R. R. Copley, M. S. Taylor, H. Riethman, U. Mudunuri, J. Peterson, M. Guyer, A. Felsenfeld, S. Old, S. Mockrin, F. Collins. Rat Genome Sequencing Project $\mathrm{C}$ Genome sequence of the Brown Norway rat yields insights into mammalian evolution. Nature 428, 493-521 (2004).

[15] M. Behrens, L. Briand, C. A. de March, H. Matsunami, A. Yamashita, W. Meyerhof, S. Weyand. Structure-Function Relationships of Olfactory and Taste Receptors. Chem Senses 43, 81-87 (2018).

[16] T. Warne, R. Moukhametzianov, J. G. Baker, R. Nehme, P. C. Edwards, A. G. Leslie, G. F. Schertler, C. G. Tate. The structural basis for agonist and partial agonist action on a beta (1)-adrenergic receptor. Nature 469, 241-244 (2011).

[17] L. Charlier, J. Topin, C. A. de March, P. C. Lai, C. J. Crasto, J. Golebiowski. Molecular modelling of odorant/olfactory receptor complexes. Methods Mol Biol 1003, 53-65 (2013).

[18] P. C. Lai, B. Guida, J. Shi, C. J. Crasto. Preferential binding of an odor within olfactory receptors: a precursor to receptor activation. Chem Senses 39, 107-123 (2014).

[19] P. C. Lai, M. S. Singer, C. J. Crasto. Structural activation pathways from dynamic olfactory receptor-odorant interactions. Chem Senses 30, 781-792 (2005).

[20] M. A. Fuertes, J. M. Pèrez, E. Zuckerkandl, C. Alonso Introns form compositional clusters in parallel with the compositional clusters of the coding sequences to which they pertain. J Mol Evol 72, 1-13 (2011). 
[21] M. A. Fuertes, C. Alonso. A method for the Annotation of Functional Similarities of Coding DNA Sequences: the Case of a Populated Cluster of Transmembrane Proteins. J Mol Evol 84, 29-38 (2016).

[22] M. A. Fuertes, J. R. Rodrigo, C. Alonso. Conserved Critical Evolutionary Gene Structures in Orthologs. J Mol Evol 87, 93-105, (2019).

[23] M. A. Fuertes, S. Lòpez-Arguello, C. Alonso, C. Evolutionary conserved compositional structures hidden in genomes of the foot-and-mouth disease virus and of the human rhinovirus. $\mathrm{Sci}$ Rep 9, 16553 (2019).

[24] Y. M. Park, S. Squizzato, N. Buso, T. Gur, R. Lopez R. The EBI search engine: EBI search as a service-making biological data accessible for all. Nucleic Acids Res 45, W545-W549 (2017).

[25] M. Safran, V. Chalifa-Caspi, O. Shmueli, T. Olender, M. Lapidot, N. Rosen, M. Shmoish, Y. Peter, G. Glusman, E. Feldmesser, A. Adato, I. Peter, M. Khen, T. Atarot, Y. Groner, D. Lancet D. Human Gene-Centric Databases at the Weizmann Institute of Science: GeneCards, UDB, CroW 21 and HORDE. Nucleic Acids Res 31, 142-146 (2003).

[26] G. Stelzer, N. Rosen, I. Plaschkes, S. Zimmerman, M. Twik, S. Fishilevich, T. I. Stein, R. Nudel, I. Lieder, Y. Mazor, S. Kaplan, D. Dahary, D. Warshawsky, Y. Guan-Golan, . Kohn, N. Rappaport, M. Safran, D. Lancet. The GeneCards Suite: From Gene Data Mining to Disease Genome Sequence Analyses. Curr Protoc Bioinformatics 54, 1.30.1-1.30.33 (2016).

[27] J. M. Young, B. J. Trask. The sense of smell: genomics of vertebrate odorant receptors. Hum Mol Genet 11, 1153-1160 (2002).

[28] D. D. Pervouchine, S. Djebali, A. Breschi, C. A. Davis, P. P. Barja, A. Dobin, A. Tanzer, J. Lagarde, C. Zaleski, L. H. See, M. Fastuca, J. Drenkow, H. Wang, G. Bussotti, B. Pei, S. Balasubramanian, J. Monlong, A. Harmanci, M. Gerstein, M. A. Beer, C. Notredame, R. Guigo, T. R. Gingeras. Enhanced transcriptome maps from multiple mouse tissues reveal evolutionary constraint in gene expression. Nat Commun 6 , 5903 (2015).

[29] G. Glusman, A. Bahar, D. Sharon, Y. Pilpel, J. White, D. Lancet. The olfactory receptor gene superfamily: data mining, classification, and nomenclature. Mamm Genome 11, 10161023 (2000).

[30] C. L. Smith, J. A. Blake, J. A. Kadin, J. E. Richardson, C. J. Bult, G. Mouse Genome Database. Mouse Genome Database (MGD)-2018: knowledgebase for the laboratory mouse. Nucleic Acids Res 46, D836-D842 (2018).

[31] V. Cherezov, D. M. Rosenbaum, M. A. Hanson, S. G. Rasmussen, F. S. Thian, T. S. Kobilka, H. J. Choi, P. Kuhn, W. I. Weis, B. K. Kobilka, R. C. Stevens. High-resolution crystal structure of an engineered human beta 2-adrenergic G proteincoupled receptor. Science 318, 1258-1265 (2007).

[32] F. Z. Chung, C. D. Wang, P. C. Potter, J. C. Venter, C. M. Fraser. Site-directed mutagenesis and continuous expression of human beta-adrenergic receptors. Identification of a conserved aspartate residue involved in agonist binding and receptor activation. J Biol Chem 263, 4052-4055 (1988).

[33] D. M. Rosenbaum, V. Cherezov, M. A. Hanson, S. G. Rasmussen, F. S. Thian, T. S. Kobilka, H. J. Choi, X. J. Yao,
W. I. Weis, R. C. Stevens, B. K. Kobilka. GPCR engineering yields high-resolution structural insights into beta 2adrenergic receptor function. Science 318, 1266-1273 (2007).

[34] W. R. Pearson. An introduction to sequence similarity ("homology") searching. Curr Protoc Bioinformatics Chapter 3, Unit 3.1 (2013).

[35] J. B. Kruskal. An overview of squence comparison. Time warps, string edits and macromolecules: the theory and practice of sequence comparison SIAM Review. CSLI Publications, Stanford University, pp. 201-237 (1983).

[36] S. B. Needleman, C. D. Wunsch. A general method applicable to the search for similarities in the amino acid sequence of two proteins. J Mol Biol 48, 443-453 (1970).

[37] L. J. Mullan, A. J. Bleasby. Short EMBOSS User Guide. European Molecular Biology Open Software Suite. Brief Bioinform 3, 92-94 (2002).

[38] S. A. Olson. EMBOSS opens up sequence analysis. European Molecular Biology Open Software Suite. Brief Bioinform 3, 87-91 (2002).

[39] M. Grossmann, B. D. Weintraub, M. W. Szkudlinski. Novel insights into the molecular mechanisms of human thyrotropin action: structural, physiological, and therapeutic implications for the glycoprotein hormone family. Endocr Rev 18, 476-501 (1997).

[40] A. P. N. Themmen, I. T. Huhtaniemi. Mutations of gonadotropins and gonadotropin receptors: elucidating the physiology and pathophysiology of pituitary-gonadal function. Endocr Rev 21, 551-583 (2000).

[41] N. Barker, H. Clevers. Leucine-rich repeat-containing Gprotein-coupled receptors as markers of adult stem cells. Gastroenterology 138, 1681-1696 (2010).

[42] S. Nakata, E. Phillips, V. Goidts. Emerging role for leucinerich repeat-containing G-protein-coupled receptors LGR5 and LGR4 in cancer stem cells. Cancer Manag Res 6, 171-180 (2014).

[43] C. A. de March, Y. Yu, M. J. Ni, K. A. Adipietro, H. Matsunami, M. Ma, J. Golebiowski. Conserved Residues Control Activation of Mammalian G Protein-Coupled Odorant Receptors. J Am Chem Soc 137, 8611-8616 (2015).

[44] A. S. Dore, K. Okrasa, J. C. Patel, M. Serrano-Vega, K. Bennett, R. M. Cooke, J. C. Errey, A. Jazayeri, S. Khan, B. Tehan, M. Weir, G. R. Wiggin, F. H. Marshall. Structure of class C GPCR metabotropic glutamate receptor 5 transmembrane domain. Nature 511, 557-562 (2014).

[45] E. Hodge, C. P. Nelson, S. Miller, C. K. Billington, C. E. Stewart, C. Swan, A. Malarstig, A. P. Henry, C. Gowland, E. Melén, I. P. Hall, I. Sayers. HTR4 gene structure and altered expression in the developing lung. Respir Res 14, 77 (2013).

[46] T. K. Bjarnadottir, D. E. Gloriam, S. H. Hellstrand, H. Kristiansson, R. Fredriksson, H. B. Schioth. Comprehensive repertoire and phylogenetic analysis of the $\mathrm{G}$ protein-coupled receptors in human and mouse. Genomics 88, 263-273 (2006).

[47] M. Johnson. Molecular mechanisms of beta (2)-adrenergic receptor function, response, and regulation. J Allergy Clin Immunol 117, 18-24 (2006). 
[48] H. C. Huang, P. S. Klein. The Frizzled family: receptors for multiple signal transduction pathways. Genome Biol 5, 234 (2004).

[49] H. Clevers, K. M. Loh, R. Nusse. Stem cell signaling. An integral program for tissue renewal and regeneration: Wnt signaling and stem cell control. Science 346, 1248012 (2014).

[50] S. Y. Hsu. New insights into the evolution of the relaxin-LGR signaling system. Trends Endocrinol Metab 14, 303-309 (2003).

[51] W. de Lau, W. C. Peng, P. Gros, H. Clevers. The Rspondin/Lgr5/Rnf43 module: regulator of Wnt signal strength. Genes Dev 28, 305-316 (2014).

[52] K. S. Carmon, X. Gong, Q. Lin, A. Thomas, Q. Liu. Rspondins function as ligands of the orphan receptors LGR4 and LGR5 to regulate Wnt/beta-catenin signaling. Proc Natl Acad Sci U S A 108, 11452-11457 (2011).

[53] R. Chen, E. V. Davydov, M. Sirota, A. J. Butte. Nonsynonymous and synonymous coding SNPs show similar likelihood and effect size of human disease association. PLoS One 5, e13574 (2010).

[54] R. Hunt, Z. E. Sauna, S. V. Ambudkar, M. M. Gottesman, C. Kimchi-Sarfaty. Silent (synonymous) SNPs: should we care about them? Methods Mol Biol 578, 23-39 (2009).

[55] S. A. Shabalina, N. A. Spiridonov, A. Kashina. Sounds of silence: synonymous nucleotides as a key to biological regulation and complexity. Nucleic Acids Res 41, 2073-2094 (2013).

[56] D. A. Drummond, J. D. Bloom, C. Adami, C. O. Wilke, F. H. Arnold. Why highly expressed proteins evolve slowly. Proc Natl Acad Sci U S A 102 (40), 14338-14343, (2005).

[57] D. A. Drummond, A. Raval, C. O. Wilke. A single determinant dominates the rate of yeast protein evolution. Mol Biol Evol 23, 327-337 (2006).

[58] D. A. Drummond, C. O. Wilke. Mistranslation-induced protein misfolding as a dominantconstraint on coding-sequence evolution. Cell 134 (2), 341-352 (2008).

[59] D. Agashe, N. C. Martinez-Gomez, D. A. Drummond, C. J. Marx. Good codons, bad transcript: large reductions in gene expression and fitness arising from synonymous mutations in a key enzyme. Mol Biol Evol 30, 549-560 (2013).

[60] M. J. Lajoie, S. Kosuri, J. A. Mosberg, C. J. Gregg, D. Zhang,
G. M. Church. Probing the limits of genetic recoding in essential genes. Science 342, 361-363 (2013a).

[61] M. J. Lajoie, A. J. Rovner, D. B. Goodman, H. R. Aerni, A. D. Haimovich, G. Kuznetsov, J. A. Mercer, H. H. Wang, P. A. Carr, J. A. Mosberg, N. Rohland, P. G. Schultz, J. M. Jacobson, J. Rinehart, G. M. Church, F. J. Isaacs. Genomically recoded organisms expand biological functions. Science 342, 357-360 (2013b).

[62] N. Ostrov, M. Landon, M. Guell, G. Kuznetsov, J. Teramoto, N. Cervantes, M. Zhou, K. Singh, M. G. Napolitano, M. Moosburner, E. Shrock, B. W. Pruitt, N. Conway, D. B. Goodman, C. L. Gardner, G. Tyree, A. Gonzales, B. L. Wanner, J. E. Norville, M. J. Lajoie, G. M. Church. Design, synthesis, and testing toward a 57-codon genome. Science 353, 819-822 (2016).

[63] J. H. Felce, S. L. Latty, R. G. Knox, S. R. Mattick, Y. Lui, S. F. Lee, D. Klenerman, S. J. Davis. Receptor Quaternary Organization Explains G Protein-Coupled Receptor Family Structure. Cell Rep 20, 2654-2665 (2017).

[64] N. Ben-Arie, D. Lancet, C. Taylor, M. Khen, N. Walker, D. H. Ledbetter, R. Carrozzo, K. Patel, D. Sheer, H. Lehrach, M. A. North. Olfactory receptor gene cluster on human chromosome 17: possible duplication of an ancestral receptor repertoire. Hum Mol Genet 3, 229-235 (1994).

[65] G. Glusman, S. Clifton, B. Roe, D. Lancet. Sequence analysis in the olfactory receptor gene cluster on human chromosome 17: recombinatorial events affecting receptor diversity. Genomics 37, 147-160 (1996).

[66] M. C. Lagerstrom, H. B. Schioth. Structural diversity of G protein-coupled receptors and significance for drug discovery. Nat Rev Drug Discov 7, 339-357 (2008).

[67] M. Nakamura, D. Yasuda, N. Hirota, T. Shimizu. Specific ligands as pharmacological chaperones: The transport of misfolded G-protein coupled receptors to the cell surface. IUBMB Life 62, 453-459 (2010).

[68] C. E. Elling, K. Thirstrup, B. Holst, T. W. Schwartz. Conversion of agonist site to metal-ion chelator site in the beta (2)-adrenergic receptor. Proc Natl Acad Sci U S A 96, 1232212327 (1999).

[69] K. Palczewski, T. Kumasaka, T. Hori, C. A. Behnke, H. Motoshima, B. A. Fox, I. Le Trong, D. C. Teller, T. Okada, R. E. Stenkamp, M. Yamamoto, M. Miyano. Crystal structure of hodopsin: A G protein-coupled receptor. Science 289, 739-745 (2000). 